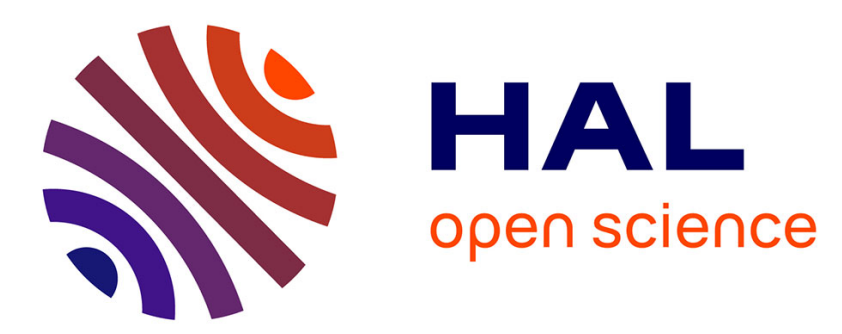

\title{
Properties of magmatic liquids by molecular dynamics simulation: The example of a MORB melt
}

Thomas Dufils, Nicolas Folliet, Boris Mantisi, Nicolas Sator, Bertrand Guillot

\section{To cite this version:}

Thomas Dufils, Nicolas Folliet, Boris Mantisi, Nicolas Sator, Bertrand Guillot. Properties of magmatic liquids by molecular dynamics simulation: The example of a MORB melt. Chemical Geology, 2016, 10.1016/j.chemgeo.2016.06.030 . hal-01346251

\section{HAL Id: hal-01346251 \\ https://hal.sorbonne-universite.fr/hal-01346251}

Submitted on 18 Jul 2016

HAL is a multi-disciplinary open access archive for the deposit and dissemination of scientific research documents, whether they are published or not. The documents may come from teaching and research institutions in France or abroad, or from public or private research centers.
L'archive ouverte pluridisciplinaire HAL, est destinée au dépôt et à la diffusion de documents scientifiques de niveau recherche, publiés ou non, émanant des établissements d'enseignement et de recherche français ou étrangers, des laboratoires publics ou privés. 


\title{
Properties of magmatic liquids by molecular dynamics simulation:
}

\section{The example of a MORB melt.}

\author{
Thomas Dufils ${ }^{1}$, Nicolas Folliet ${ }^{1,2}$, Boris Mantisi ${ }^{1}$, Nicolas Sator ${ }^{1}$ and Bertrand Guillot ${ }^{1}$ \\ ${ }^{1}$ UPMC Univ Paris 06, UMR CNRS 7600, LPTMC, Sorbonne Universités, F 75005, Paris, France, \\ ${ }^{2}$ Tectospin, Institut Lavoisier de Versailles, UMR CNRS 8180, Université de Versailles St-Quentin en Yvelines, \\ F 78035, Versailles, France
}

\begin{abstract}
A new atom-atom interaction potential is introduced for describing by classical molecular dynamics (MD) simulation the physical properties of natural silicate melts. The equation of state, the microscopic structure, the viscosity, the electrical conductivity, and the selfdiffusion coefficients of ions in a mid-oceanic ridge basalt (MORB) melt are evaluated by MD over a large range of temperature and pressure $(1673-3273 \mathrm{~K}$ and $0-60 \mathrm{GPa})$. A detailed comparison with experimental data shows that the model reproduces the thermodynamic, structural and transport properties of a MORB with an unprecedented accuracy. In particular, it is shown that the MORB melt crystallizes at lower mantle conditions into a perovskite phase whose the equation of state (EOS) is compatible with those proposed in the experimental literature. Moreover, in accordance with experimental findings, the simulation predicts not only that the MORB viscosity exhibits a (slight) minimum with the pressure, but also that the viscosity at high temperature remains very low $(<100 \mathrm{mPa}$.s for $\mathrm{T}>$ $2273 \mathrm{~K}$ ) even at high pressure (up to $40 \mathrm{GPa}$ ). However the evolution of the electrical conductivity with temperature and pressure is not always the symmetrical of that of the viscosity. In fact, the relationship between viscosity and electrical conductivity shows a crossover at around $2073 \mathrm{~K}$.
\end{abstract}

Keywords: Classical molecular dynamics simulations, mid-oceanic ridge basalt, EOS, liquid structure, self-diffusion coefficients, viscosity, electrical conductivity. 


\section{Introduction}

Magmatic liquids play a key role in the evolution of terrestrial planets. On Earth, magmas issued from volcanic activity have continually resurfaced the planet whereas at depth in the mantle, chemical mixing and transport of volatiles over geological time are driven by liquids coming from partial melting (Eiler, 2003). So to predict how these incipient liquids behave at depth (buoyancy and mobility, for instance), it is of vivid importance to have an accurate knowledge of their physical properties. Although important advances in high pressure-high temperature (HP-HT) techniques have been made in the last two decades, the properties of silicate liquids at mantle conditions (i.e. from the crust to the core-mantle boundary) are still poorly known (Ohtani, 2009). Our purpose is to show that classical molecular dynamics (MD) simulations are useful to sketch a broad and quantitative picture of natural silicate melt properties at mantle conditions. We will treat in the following the example of a mid-oceanic ridge basalt (MORB) composition which is representative of the basaltic oceanic crust. Major element compositions of MORBs are very uniform worldwide (Klein and Langmuir, 1987) and it is believed that after oceanic subduction, some of these basalts can reach the lower mantle without presenting a significant alteration (except for the volatiles, mainly $\mathrm{H}_{2} \mathrm{O}$ and $\mathrm{CO}_{2}$, which on average are in low contents ( Saal et al., 2002)). Moreover a wealth of experimental data on the properties of MORBs are available and especially in the HP-HT range (Agee, 1998; Ohtani and Maeda, 2001; Sanloup et al., 2013; Sakamaki et al., 2013), which renders the comparison with the MD calculations more exhaustive than it could be with other natural compositions.

Our classical MD simulations are based on a new empirical force field which is an improvement of a previous one developed by two of us (Guillot and Sator, 2007a,b) for describing silicate liquids in the nine component system $\mathrm{K}_{2} \mathrm{O}-\mathrm{Na}_{2} \mathrm{O}-\mathrm{CaO}-\mathrm{MgO}-\mathrm{FeO}-\mathrm{Fe}_{2} \mathrm{O}_{3}-\mathrm{Al}_{2} \mathrm{O}_{3}-\mathrm{TiO}_{2}-\mathrm{SiO}_{2}$ (KNCMFATS). This new model potential is presented in section 2 with the computational methodology. The results of the MD calculations are given in section 3. In particular we will focus on the compressibility of the MORB melt and compare the MD results with various experimental data of the literature which are showing a rather large dispersion between each other. Next, we will show that under a high compression rate the simulated liquid spontaneously crystallizes into a perovskite-like structure 
defining a melting line reasonably close to those recently proposed for MORB (Andrault et al., 2014; Pradhan et al., 2015). The densification of the melt under pressure is accompanied by structural modifications which can be followed by in situ X-ray diffraction experiment (e.g. Sanloup et al., 2013). However the interpretation of these X-ray data is not straightforward and it will be shown how useful are the MD calculations in identifying the main atom-atom contributions to the X-ray pair distribution function. With regard to transport properties, they can be evaluated by MD over a large range of thermodynamic conditions. It is pointed out that the calculated viscosity exhibits a minimum value with the pressure in the temperature range $1673-2273 \mathrm{~K}$, in accordance with experimental data (Ando et al., 2003; Sakamaki et al., 2013). Moreover, at high temperature, the viscosity remains very low $(<100 \mathrm{mPa} . \mathrm{s})$ even at very high pressure $(>10 \mathrm{GPa})$. Correlatively, it is found that the pressure behavior of the electrical conductivity varies with the temperature. An interesting outcome is that the relationship between viscosity and electrical conductivity does not follow a simple law.

\section{Simulation method.}

Classical and $a b$ initio MD simulations have been widely used in the last three decades for investigating melt properties and structure of various geomaterials (e.g. Angell et al., 1987; Matsui, 1996; Stixrude and Karki, 2005; Guillot and Sator, 2007a,b; Ben Martin et al., 2012; Bajgain et al., 2015). However, complex compositions like those involved in terrestrial magmas (e.g. basalts) are rarely tackled yet by MD simulations. In this context we made the choice of performing classical MD simulations instead of $a b$ initio MD (AIMD) simulations because the latter ones are much more expensive in computer time (by roughly three orders of magnitude). Thus AIMD does not allow to investigate with the required accuracy the transport properties of natural magmatic compositions (with, at least, nine major oxides) at conditions prevailing in the Earth's mantle. As a matter of fact, when dealing with AIMD calculations, present day computational resources are limiting system size and run duration to a few hundred atoms and a few tens of ps (for a review see Karki, 2015), whereas the trajectory of thousands of atoms over running time of several tens of ns $\left(10^{-9} \mathrm{~s}\right)$ can be routinely 
carried out with classical MD codes. However the price to pay for this choice is the use (and the development) of a reliable force field for describing the interactions into magmatic liquids.

Some years ago two of us have proposed a simple empirical pair potential to describe silicate melts in the KNCMFATS system (Guillot and Sator, 2007a,b). It has been shown that the equation of state (EOS) and the structure of felsic to ultra-mafic melts are well reproduced by this empirical force field but that their transport properties are not always well reproduced, in particular the simulated melts are less viscous than the real ones. A feature which has been reported in many MD studies dealing with empirical pair potentials (e.g. Lacks et al, 2007; Spera et al., 2011; Ben Martin et al., 2012; Bauchy et al., 2013). To remedy this shortcoming, we introduce an improved force field which, among other things, explicitly accounts for a degree of covalence between cations and oxygens of the melt. Following the same rationale as in the original 2007 pair potential, the interaction energy between atoms of a melt belonging to the KNCMFATS system is given by a sum of pairwise contributions,

$v\left(r_{i j}\right)=\frac{z_{i} z_{j}}{r_{i j}}-A_{i j} e^{-\left(\frac{r_{i j}-l_{i j}}{\lambda}\right)^{2}}+B_{i j} e^{-\left(\frac{r_{i j}}{\rho_{i j}}\right)}-\frac{C_{i j}}{r_{i j}^{6}}$

where $r_{i j}$ is the distance between atoms $i$ and $j, z_{i}$ is the effective charge associated with the atom $i$, and where $A_{i j}, l_{i j}, \lambda, B_{i j}, \rho_{i j}$ and $C_{i j}$ are parameters describing covalent, repulsive and dispersive forces, respectively. To ensure the transferability of the interaction potential with the melt composition, the electroneutrality of the oxide components (e.g. $\mathrm{SiO}_{2}, \mathrm{Al}_{2} \mathrm{O}_{3}$,..) is assumed, that is the valence of the oxygen is kept fixed irrespective of its environment. Moreover its value is set equal to $-0.945 \mathrm{e}$, as in the 2007 potential. The parameters $A_{i j}$ and $\lambda$, associated with the cation-oxygen covalent energy, were determined from the theory of polar covalence proposed by Sanderson in the eighties (see the Appendix for further details). The parameters $C_{i j}$ associated with dipole-dipole dispersion energy between atoms $\mathrm{i}$ and $\mathrm{j}$ are evaluated from the Slater-Kirkwood formula (see the Appendix). As for the coefficients $B_{i j}$ and $\rho_{\mathrm{ij}}$, associated with the repulsion energy, they were determined from a series of MD calculations investigating melts of various compositions (rhyolitic, andesitic, basaltic, peridotitic and others chosen in the CMAS system) so as the density and the cation-oxygen distances of each simulated melt reproduce at best the corresponding density (Lange and Carmichael, 1987; Courtial and 
Dingwell, 1999) and structure data at atmospheric pressure (Brown et al., 1995). The final set of potential parameters is given in Table 1.

For the sake of computational efficiency, the MD simulations were performed with the DL-POLY 2.0 code (Smith and Forester, 1996) when a small system size (1,000 or 3,000 atoms) was required, and with the LAMMPS code (Plimpton, 1995) when it was necessary to deal with a large system size (648,000 atoms), these two MD codes leading to the same results for a given set of simulation parameters. The simulation box is cubic with periodic boundary conditions and the equations of motion of atoms interacting through the above force field are solved by the Verlet's algorithm with a time step of $1 \mathrm{fs}\left(10^{-15} \mathrm{~s}\right)$. The long range Coulomb interactions between ions are accounted for by a Ewald sum. The calculations are performed in the isothermal isobaric ensemble for evaluating thermodynamic and structure properties, and in the microcanonical ensemble for evaluating the transport properties (self-diffusion coefficients, viscosity, and electrical conductivity). MD trajectories were pursued for a large running time (10 ns or more) to ensure a good accuracy of the averaged properties. Thus the statistical uncertainty is less than $1 \%$ for T, $\mathrm{P}$ and the density $(n)$, a few percent for the self-diffusion coefficients (except for elements in low concentration as $\mathrm{K}$ or $\mathrm{Na}$ for which the uncertainty may reach $10 \%$ or more), and of the order of $10 \%$ for the viscosity and the electrical conductivity. The composition of the investigated melt is that of an oceanic ridge basalt from the midAtlantic ridge (TK21B, Reynolds and Langmuir, 1997): $50.6 \mathrm{wt} \% \mathrm{SiO}_{2}, 1.5 \mathrm{wt} \% \mathrm{TiO}_{2}, 15.1 \mathrm{wt} \%$ $\mathrm{Al}_{2} \mathrm{O}_{3}, 1.1 \mathrm{wt} \% \mathrm{Fe}_{2} \mathrm{O}_{3}, 8.4$ wt $\% \mathrm{FeO}, 7.8 \mathrm{wt} \% \mathrm{MgO}, 11.9$ wt $\% \mathrm{CaO}, 2.9 \mathrm{wt} \% \mathrm{Na}_{2} \mathrm{O}$, and $0.1 \mathrm{wt} \%$ $\mathrm{K}_{2} \mathrm{O}$.

\section{Results}

\subsection{Equation of state and MORB melting curve}

In order to propose an equation of state (EOS) of our basaltic melt valid over a large pressuretemperature range we have evaluated by MD the evolution of the density with pressure along several isotherms between 1673 and $3273 \mathrm{~K}$ in the pressure range 0-60 GPa. In a density versus pressure representation, these isotherms can be fitted in the pressure range 0-30 GPa, by a third-order Birch- 
Murnaghan EOS (BMEOS) with an accuracy better than $1 \%$ (i.e. within the numerical uncertainties of the MD calculation),

$P=\frac{3}{2} K_{T}\left\{\left(\frac{n}{n_{\text {ref }}}\right)^{7 / 3}-\left(\frac{n}{n_{\text {ref }}}\right)^{5 / 3}\right\}\left\{1-\frac{3}{4}\left(4-K^{\prime}\right)\left[\left(\frac{n}{n_{\text {ref }}}\right)^{2 / 3}-1\right]\right\}$,

where $P$ is the pressure, $K_{T}$ the isothermal bulk modulus at temperature $T, K^{\prime}$ its pressure derivative, $n$ the density of the melt at $T$ and $P$, and $n_{r e f}$ the reference density of the melt at temperature $T$ and pressure $P=1$ bar. It is suitable to evaluate the density $n_{r e f}$ at temperature $T$ from the density $n_{r e f}^{0}$ at a reference temperature $T_{0}$ in using the following relation,

$n_{\text {ref }}(T)=n_{r e f}^{0} \exp \int_{T_{0}}^{T}-\alpha(T) d T$

where the thermal expansion coefficient, $\alpha(T)$, is a linear function of the temperature,

$\alpha(T)=\alpha_{0}+\alpha_{1} T$.

In the same way the bulk modulus at temperature $T$ is given by a simple polynomial function,

$K_{T}=K_{T_{0}}\left(1-b_{1}\left(T-T_{0}\right)-b_{2}\left(T-T_{0}\right)^{2}\right)$.

The reference temperature $T_{0}$ is equal to $1673 \mathrm{~K}$, and after fitting of the MD simulation data, the final parameters of the BMEOS are the following: $n_{r e f}^{0}=2.65 \mathrm{~g} / \mathrm{cm}^{3}, \alpha_{0}=0.7010^{-4} \mathrm{~K}^{-1}, \alpha_{1}=1.510^{-8} \mathrm{~K}^{-2}$, $K_{T_{0}}=20.5 \mathrm{GPa}, b_{1}=3.510^{-4} \mathrm{~K}^{-1}, b_{2}=-5.510^{-8} \mathrm{~K}^{-2}$, and $K^{\prime}=5.2$.

The evolution of the density with pressure at different temperatures between 1673 and $2673 \mathrm{~K}$ is shown in Fig.1 and is compared with compressibility data of the literature. An excellent agreement is obtained with the densities measured in sink-float experiments. Thus Agee (1998) found a value of $3.14 \mathrm{~g} / \mathrm{cm}^{3}$ at $\sim 1950 \mathrm{~K}$ and $5.85 \mathrm{GPa}$ as compared with $3.12 \mathrm{~g} / \mathrm{cm}^{3}$ by MD, whereas Ohtani and Maeda (2001) determined a MORB density of about $3.50 \mathrm{~g} / \mathrm{cm}^{3}$ at $15.1 \pm 0.7 \mathrm{GPa}$ and $2773 \mathrm{~K}$, and $3.53 \mathrm{~g} / \mathrm{cm}^{3}$ at $14.9 \pm 0.5 \mathrm{GPa}$ and $2473 \mathrm{~K}$ when we obtain 3.49 and $3.53 \mathrm{~g} / \mathrm{cm}^{3}$ at the same $(\mathrm{P}, \mathrm{T})$ conditions. More recently Sakamaki et al. (2013) measured by X-ray absorption spectroscopy using a piston-cylinder type press the density of a MORB melt in the temperature-pressure range $1673-2000 \mathrm{~K}$ and $1.2-4.5$ GPa. Their values are lower than the calculated ones by 1.8 to $6.5 \%$ depending on the (P,T) conditions under investigation (see Fig.1). In order to investigate the MORB compressibility at more extreme (T,P) conditions, Sanloup et al. (2013) determined the melt density from a X-ray diffraction 
experiment using a laser-heated diamond anvil cell. In the investigated range (2200 - $3273 \mathrm{~K}, 10.5$ - 60 GPa) the density values extracted from the X-ray data are higher than the simulated ones by 6.8 to 9.8 $\%$, a significant deviation (see Fig.1). However, the density values of Sanloup et al. (2013) deviate by $+7 \%$ from the values of Ohtani and Maeda (2001) at 2473-2773 K and $15 \mathrm{GPa}$, and are incompatible with the low pressure data (1 6 GPa) of Sakamaki et al. (2013) and Agee (1998). The slight differences in composition between the basaltic melts investigated in these studies are too small to explain the discrepancy. Lately Bajgain et al. (2015) have evaluated by first principles MD simulation the EOS of a model MORB and found densities significantly smaller than that of Sanloup et al. (e.g. $4 \%$ at $3000 \mathrm{~K}$ and $45 \mathrm{GPa}$ in the framework of the LDA approximation, and - $10 \%$ within the more accurate GGA approximation). Thus, our MD simulation data are in very good agreement with the first principles MD calculations of Bajgain et al. (2015) dealing in the framework of the GGA approximation.

It happened that under compression and at a sufficiently high temperature (> $2400 \mathrm{~K}$ ) our simulated MORB melt crystallizes in a perovskite-like structure. The resulting crystal occupies most of the simulation box when the size of the system is small (e.g. 3,000 atoms) but with a much larger system size the final state is a polycrystal. As shown in Fig.2, the EOS of this perovskite (Pv) crystal is very close to the one obtained experimentally by Ono et al. (2005) and slightly below those determined by Hirose et al. (2005) and by Ricolleau et al. (2010). Moreover, the fitting of our pressure-density simulation data at $300 \mathrm{~K}$ by a third-order BMEOS leads to $K_{0}=223 \mathrm{GPa}$ and $n_{0}=4.25 \mathrm{~g} / \mathrm{cm}^{3}$ when $K$, is fixed equal to 4 , those values being virtually identical to the ones $\left(K_{0}=222 \pm 6 \mathrm{GPa}\right.$ with $K^{\prime}=4$, and $n_{0}=4.22 \pm 0.02 \mathrm{~g} / \mathrm{cm}^{3}$ ) obtained by Hirose et al. (2005) for the HP assemblage. In fact the crystalline assemblage observed experimentally is composed of 5 phases ( $\mathrm{Mg}-\mathrm{Pv}, \mathrm{Ca}-\mathrm{Pv}$, stishovite, $\mathrm{NaL}$, and $\mathrm{CaFe}_{2} \mathrm{O}_{4}$-type structure) whereas in the simulation only one perovskite phase is observed but with a similar EOS. More precisely the MD-generated perovskite phase (cubic) accommodate most of the network modifier cations of the melt $(\mathrm{Fe}, \mathrm{Mg}, \mathrm{Ca}, \mathrm{Na}$, and $\mathrm{K})$ when the simulated system is small, whereas for a large system size, the crystallization takes place through an homogeneous nucleation process where about one hundred crystallites are nucleating in the melt and are growing up with the running time of the simulation (a movie of the liquid-solid transition can be seen on 
http//www.lptmc.jussieu.fr/user/bmantisi/BasaltLiq2Cryst/BasaltLiq2Cryst.mp4). For instance at 3273 $\mathrm{K}$ and $60 \mathrm{GPa}$, after a few ns the crystallites are mostly in contact with each other, the space between them being filled by an interstitial melt forming grain boundaries and pockets. After a certain time $(\sim 10 \mathrm{~ns})$ the system seems to reach a solid-liquid equilibrium as the density of the whole system (solid+melt) shows a plateau value and the crystallites cease to grow up (the melt fraction is then equal to $\sim 50 \%$ ). The composition of the perovskite-bearing solid phase (all the crystallites of the simulation box have on average the same composition and the same structure) is Ca-rich and is enriched in $\mathrm{SiO}_{2}$, $\mathrm{TiO}_{2}, \mathrm{MgO}, \mathrm{FeO}, \mathrm{Na}_{2} \mathrm{O}$, and $\mathrm{K}_{2} \mathrm{O}$ with respect to the $\mathrm{MORB}$ original composition while the coexisting melt is depleted in the latter oxides but is enriched in $\mathrm{Al}_{2} \mathrm{O}_{3}$ (see Table 2). The finding that the perovskite phase is $\mathrm{Ca}$-rich is in accordance with the observation that $\mathrm{Ca}-\mathrm{Pv}$ is the liquidus phase of MORB in this T-P range $\left(\mathrm{T}>2473 \mathrm{~K}\right.$ and $\mathrm{P}>25 \mathrm{GPa}$ ) and the fact that the melt is enriched in $\mathrm{Al}_{2} \mathrm{O}_{3}$ and depleted in $\mathrm{SiO}_{2}$ is also in agreement with the observation of Pradhan et al. (2015). Nevertheless this Ca-rich perovskite phase is likely metastable and the simulation time necessary to overcome the energy barrier for the system to be restructured in a 5-solid phases is out of reach with our computational resources. Moreover, our finding that at $3273 \mathrm{~K}$ and $60 \mathrm{GPa}$ the melt fraction is high $(\sim 50 \%)$ does not necessarily mean that this state point is far from the solidus. As a matter of fact, although our system size is quite large with respect to the state of the art in MD simulations, it is still very small with respect to an experimental sample (our grain size is of the order of $10 \mathrm{~nm}$ instead of $1000 \mathrm{~nm}$ or much more in the true life). Even at subsolidus condition the grain boundaries in a polycrystal occupy a volume fraction as high as $\sim 30 \%$ when grain sizes are of the order of $10 \mathrm{~nm}$ whereas it is much less than $0.1 \%$ with grain sizes of 1 micron and larger. Hence it is likely that the simulated point at $3273 \mathrm{~K}$ and $60 \mathrm{GPa}$ is located near the solidus of our model, but the simulation time at our disposal is not long enough to observe a reorganization of the system into a polyphasic assemblage (5 solid phases + melt).

From a theoretical viewpoint the melting curve of a solid simulated by MD can be evaluated by following in a density-pressure representation the liquid-solid phase transition along several isotherms. The melting pressure is estimated by locating the mid-point of the loop connecting the liquid and the solid branches of a given isotherm. In the present case this method leads to an ambiguous result 
because when the system crystallizes under pressure (in one grain or in a polycrystalline structure, according to the size of the simulated system) we don't know how far the system is from the solidus (liquidus). So the locus associated with the mid-points of the isothermal loops corresponds to a line located somewhere in between the liquidus and the solidus. Thus in a temperature-pressure representation, this method only leads to a lower bound for the liquidus and to an upper bound for the solidus. The line reported in the inset of Fig.2 (labeled $L-S$ ) corresponds to the liquid-solid transition observed in the small simulation box (3,000 atoms). It turns out that this line is located in between the liquidus and the solidus reported by Andrault et al. (2014) and above the solidus evaluated by Pradhan et al. (2015). Furthermore, the state point at $3273 \mathrm{~K}$ and $60 \mathrm{GPa}$ (labelled $S$ in Fig.9), that we think to be close to the solidus of our model at $60 \mathrm{GPa}$ (see the above discussion about the formation of a polycrystal), is located near the solidus of Pradhan et al. (2015) and the one determined by Hirose et al. (1999) in this (P, T) range. Nevertheless it is noteworthy that it is not easy (or accurate) to evaluate the melting curve of a multi-component system by MD simulation and it is certainly preferable to use another route (e.g. Pedersen, 2013) or alternative approaches like those based on chemical and thermodynamic models (e.g. Pelton and Blender, 1986; Ottonello et al., 2013; Belmonte et al., 2014).

\subsection{Structural evolution of molten MORB with pressure.}

Information on the microscopic structure of a liquid can be obtained from the evaluation of the pair distribution functions (PDF) between elements composing the melt. For a MORB melt there are 55 different PDF's in counting only the 10 major elements. With the advent of synchrotron radiation sources the structure of magmatic melts at HP-HT can be investigated in situ by collecting X-ray diffraction data (e.g. Funamori et al., 2004). In a X-ray diffraction experiment, the total PDF, $G_{X}(R)$, is calculated from the k-dependent structure factor, $\mathrm{S}(\mathrm{k})$, by the equation,

$G_{X}(R)=\frac{1}{2 \pi^{2} R \rho} \int_{0}^{\infty} k S(k) \sin (k R) d k$

where $\rho=N / V$ is the atomic density of the liquid and $S(k)$ the structure factor defined by,

$S(k)=\rho \sum_{i, j}^{N} C_{i} C_{j} f_{i j}(k) \int_{0}^{\infty} r\left(g_{i j}(r)-1\right) \frac{\sin (k r)}{k} d r$ 
In this equation, $C_{i}$ is the mole fraction of atomic species $i, g_{i j}(r)$ is the PDF between atoms $i$ and $j$, and $f_{i j}(k)$ is defined from the tabulated k-dependent atomic scattering factors $f_{i}(k)$ (Waasmeier and Kirfel, 1995) by the relation,

$f_{i j}(k)=f_{i}(k) f_{j}(k) /\left[\sum_{i=1}^{N} C_{i} f_{i}(k)\right]^{2}$.

Because of the MORB composition the contributions of $\mathrm{Si}$ and $\mathrm{O}$ atoms to $\mathrm{S}(\mathrm{k})$ are predominant, and because of the relative weight of the atomic structure factors (related to the number of electrons of the considered element), the contributions coming from heavy elements (e.g. Fe, $\mathrm{Ca}$, and $\mathrm{Ti}$ ) are enhanced with respect to those of lighter elements (e.g. $\mathrm{Mg}$ and $\mathrm{Na}$ ). The total pair distribution function, $\mathrm{G}_{\mathrm{X}}(\mathrm{R})$, and its decomposition in (principal) individual components are shown in Fig.3 for the simulated MORB melt at $1673 \mathrm{~K}$ and atmospheric pressure.

Clearly, the MD simulation is the right tool for pointing out what are the pairs of atoms which really contribute to the X-ray PDF. The latter one is characterized by nine peaks (or bumps) indicated in Fig. 3 by the letters $\mathbf{a}, \mathbf{b}, \mathbf{c}, \mathbf{d}, \mathbf{e}, \mathbf{f}, \mathbf{g}, \mathbf{h}$, and $\mathbf{i}$, respectively. These structural features primarily originate from ten PDF's, the contribution of the 45 others being nearly negligible. More precisely, the first peak (labelled a) at $\mathrm{R} \sim 1.65 \mathrm{~A}$ comes from the Si-O bonds, the Al-O bonds ( $\mathrm{R} \sim 1.75 \mathrm{~A}$ ) being not visible in this R-range (however, notice the slight enlargement at the basis of the $\mathrm{SiO}$ peak). The second peak (b) at about 2.0 A comes from the combination of $\mathrm{Fe}^{2+}-\mathrm{O}$ and $\mathrm{Mg}-\mathrm{O}$ bonds (the $\mathrm{Fe}^{2+} \mathrm{O}$ contribution being predominant), and the minimum between peaks $\mathbf{a}$ and $\mathbf{b}$ is partially filled by the contributions of $\mathrm{TiO}$ and $\mathrm{Fe}^{3+} \mathrm{O}$ at about $1.90 \mathrm{~A}$. The shoulder (c) near 2.4 A is generated by $\mathrm{Ca}-\mathrm{O}$ and Na-O bonds, whereas the peaks (d) and (e) are due to $\mathrm{OO}$ and $\mathrm{SiSi}$ correlations in the first shell of neighbors. The peak (f) expresses the $(\mathrm{SiO})_{2}$ correlations in the second shell of neighbors and the peak $(\mathrm{g})$ is generated by the combination of $(\mathrm{OO})_{2}$ and $(\mathrm{SiSi})_{2}$ correlations in the second shell of neighbors. Finally, the peaks (h) and (i), barely visible, are resulting from $(\mathrm{SiSi})_{3}$ and $(\mathrm{OO})_{3}$ correlations between atoms separated by two shells of neighbors. On average, the total PDF issued from MD is in a reasonable agreement with the one extracted from a X-ray diffraction experiment on liquid basalt by Drewitt et al. (2013). Nevertheless the shoulder (c) at 2.4 A was interpreted by these authors as due to 
the presence of $\mathrm{FeO}_{6}$ coordination when we assign this feature mainly to the contribution of $\mathrm{CaO}$ bonds (compare Fig.3 with Fig.7 in Drewitt et al., 2013).

The X-ray PDF exhibits significant changes under pressure, with the general trend that the temperature, when it is increased concomitantly with the pressure, renders smoother the profile of the PDF. As illustrated in Fig.4, when the pressure is increased, the magnitude of the first peak (a) decreases and the peak (b) is less prominent, the latter becoming barely visible above $2673 \mathrm{~K}$ and 30 GPa. The shoulder (c) and the peak (d) tend to merge with each other and are resolved as a unique peak when the pressure reaches $30 \mathrm{GPa}$ and beyond. When the pressure exceeds $\sim 10 \mathrm{GPa}$ the contribution of $\mathrm{SiSi}$ correlations to the peak (e) decreases somewhat to the benefit of $\mathrm{SiAl}$ ans $\mathrm{SiCa}$ correlations, a feature which gives rise to a broad peak (e) at about $3 \mathrm{~A}$. Above $\mathrm{R}=4 \mathrm{~A}$ the structural order lessens and shrinks under compression and peaks (f), (g) and (i) become very smooth while the peak (h) is no more visible. All these features compare well with X-ray diffraction data obtained at similar (P,T) conditions by Sanloup et al. (2013), although in the latter case the peak (b), at about 2 A, is not clearly seen and the successive peaks visible above $4 \mathrm{~A}$ do not seem to evolve in a regular manner with the pressure (see Fig.1 in Sanloup et al., 2013).

In contrast, the PDF associated with the perovskite phase (Pv) shows a pronounced structural order at intermediate and large distances (see Fig.4). In particular the peaks e, f, and $\mathbf{g}$, and the new peaks d', $\mathbf{g}$, and $\mathbf{j}$ are signatures of the crystalline order. More precisely, the fourth peak (d) corresponds to distances (all equal on average) between $\mathrm{Si}$ and the cations $\mathrm{Ca}, \mathrm{Fe}^{2+}, \mathrm{Mg}, \mathrm{Na}$ or $\mathrm{K}$, located in the interstitial space formed by the eight neighboring $\mathrm{SiO}_{6}$ octahedra ( $\mathrm{Al}$, $\mathrm{Ti}$ and $\mathrm{Fe}^{3+}$ also form $\mathrm{TO}_{6}$ octahedra), and the corresponding Si atoms. The fifth peak (e) corresponds to SiSi, AlAl, SiAl, and $\mathrm{XY}$ (where $\mathrm{X}, \mathrm{Y}=\mathrm{Ca}, \mathrm{Fe}^{2+}, \mathrm{Mg}, \mathrm{Na}$, and $\mathrm{K}$ ) first neighbor distances. The same rationale can be found for the other peaks (for an assignment see the legend of Fig.4).

To characterize the evolution with pressure of the melt structure at short range it is usual to evaluate the pressure dependence of the number of oxygens around the cations (cation coordination number). As reported in Fig.5, the coordination number of network former cations $\mathrm{Si}$ and $\mathrm{Al}$ increases progressively from a value equal to $\sim 4$ at low pressure up to a value of $\sim 5.1$ for $\mathrm{Si}$ and $\sim 5.6$ for $\mathrm{Al}$ at $40 \mathrm{GPa}$, a value which is equal to 6 in the perovskite crystal. In passing notice that when the 
coordination number of Si reaches a value of about 5 in the melt (that is for $\mathrm{P} \sim 35 \mathrm{GPa}$ ), the EOS begins to deviate somewhat from a third-order BMEOS (see the inset in Fig.1) and a fourth-order BMEOS is needed to improve the fitting of the simulation data. This change of the MORB compressibility above $35 \mathrm{GPa}$ was pointed out before by Sanloup et al. (2013). For Ti the coordination number evolves between 5.9 and 6.7 in the pressure range $0-40 \mathrm{GPa}$ (as compared with $\sim 5$ in molten $\mathrm{TiO}_{2}$ at $2250 \mathrm{~K}$, after Alderman et al., 2014), and reaches 9 in the perovskite because in this crystal Ti can be 6-coordinated (like $\mathrm{Si}$ and $\mathrm{Al}$ ), or 12-coordinated as the alkali and alkaline-earth cations. In the same way, the coordination number of $\mathrm{Fe}^{3+}$ amounts to $\sim 5$ at low pressure, $\sim 6$ at very high pressure in the melt (> $30 \mathrm{GPa}$ ) and reaches $\sim 10$ in the perovskite. As for $\mathrm{Fe}^{2+}$, it shows a coordination number very close to that of $\mathrm{Fe}^{3+}$ at low pressure $(\sim 5.5)$ but it increases more steeply with the pressure $(\sim 6.8$ at $25 \mathrm{GPa}$ ) and is equal to 12 in the perovskite. The coordination number of $\mathrm{Mg}$ behaves mostly as the one of $\mathrm{Fe}^{2+}$ (from $\sim 4.9$ at low pressure up to $\sim 7$ at high pressure, see Fig.5) and is close to that observed in magnesian silicate liquids ( $\sim 5.1$ at low pressure, after Wilding et al., 2010). In contrast, Ca and $\mathrm{Na}$ show a larger coordination number $(\sim 7$ at low pressure and $\sim 9-10$ at high pressure, as compared with a value around $\sim 5.0$ for $\mathrm{Ca}$ in molten $\mathrm{CaSiO}_{3}$ at $1923 \mathrm{~K}$, after Skinner et al., 2012). As for $\mathrm{K}$, despite a lower statistics, its coordination number is high (because of its size) and practically invariant with the pressure ( 11 in the melt and 12 in the perovskite).

There is a great amount of experimental studies aiming at the quantification of the structural transformation induced by pressure and composition on silicate glasses (for a few examples see Xue et al., 1991; Lee et al., 2006; Allwardt et al., 2007; and for a review see Mysen and Richet, 2005). A common trend pointed out in some of these studies is the increase of the $\mathrm{Si}$ - and Al- coordination numbers with the pressure, the Al-coordination increasing more rapidly with the pressure than the Sicoordination does (see also Crépisson et al., 2014). Although these trends are conspicuous in our simulation data, a direct comparison with structure data obtained with silicate glasses is not fully satisfying because the glassy state can induce a structural reorganization around some cations (e.g. Benmore et al., 2010; Vercamer et al., 2015). Only a few studies, using in situ X-ray or neutron diffraction techniques, give some insights on the structure of silicate melts at liquidus temperature (e.g. Funamori et al., 2004; Benmore et al., 2010; Cristiglio et al., 2010; Drewitt et al., 2013) but most 
of these studies are restricted to low pressures. In contrast, Sanloup et al. (2013) have investigated a MORB composition in a laser-heated diamond anvil cell and have reported that the Si-coordination evolves from $\sim 4.5(0.2)$ at $15 \mathrm{GPa}$ to about $\sim 6.0(0.1)$ at $35 \mathrm{GPa}$, an evolution more marked than that predicted by our MD calculations ( $\sim 4.2$ by MD instead of $\sim 4.5(0.2)$ at $15 \mathrm{GPa}, \sim 4.4$ instead of $\sim$ $5.4(0.2)$ at $25 \mathrm{GPa}$, and $\sim 5.0$ instead of $\sim 6.0(0.1)$ at $35 \mathrm{GPa})$. However the determination of the Sicoordination number from the experimental X-ray pair distribution function is not free of adjustable parameters and we have emphasized that the density of the MORB melt issuing from the above study is systematically higher than the one observed in other experimental studies. These inaccuracies could lead to an overestimation of the Si- coordination number. In fact the pressure evolution of the Sicoordination number in our simulated MORB is quite similar to the one observed in silica glass up to 30 GPa (Benmore et al., 2010; Sato and Funamori, 2010; Zeidler et al., 2014) whereas in the 30-40 GPa range the Si- coordination increases less rapidly than in silica glass (the 5-fold coordination is dominant in the simulated melt up to $40 \mathrm{GPa}$ whereas a rapid increase from 5-fold to 6-fold coordination is observed in silica glass between 30 and $40 \mathrm{GPa}$ ). But our finding of a dominant 5 -fold Si coordination in this pressure range is in agreement with the AIMD simulation data reported for liquid diopside (Sun et al., 2011) and for a MORB melt (Bajgain et al., 2015).

\subsection{Viscosity.}

A transport property of fundamental interest for geodynamics is the viscosity. When the evolution of the viscosity of basaltic melts with the temperature is rather well documented (e.g. Shaw, 1969; Murase and McBirney, 1973; Villeneuve et al., 2008), its evolution with the pressure is poorly known and especially at very high pressure and temperature (Scarfe, 1973; Kushiro et al., 1976; Ando et al., 2003, Sakamaki et al., 2013). Here, the viscosity of the simulated MORB melt has been evaluated from the Green-Kubo relation (Allen and Tildesley, 1987) relating the viscosity to the time autocorrelation function of the stress tensor (many MD studies have used this expression, see for instance Karki and Stixrude, 2010). The evaluation of the viscosity by this relation is accurate as long as $\mathrm{t}_{\text {run }} \gg \tau_{\text {relax }}$, where $\mathrm{t}_{\text {run }}$ is the time duration of the simulation and $\tau_{\text {relax }}$ is the shear relaxation time. An estimate of $\tau_{\text {relax }}$ is given by the Maxwell relation, $\tau_{\text {relax }}=\eta / G_{\infty}$, where the shear modulus at 
infinite frequency $G_{\infty}$ is equal to $\sim 3-30 \mathrm{GPa}$ for silicate melts (Dingwell and Webb, 1989). Hence, a melt of viscosity about 100 Pa.s has a time relaxation for viscous flow of about 3-30 ns according to the Maxwell relation. This rough estimation indicates that to properly evaluate a melt viscosity of this magnitude it is necessary to carry out a MD simulation run much longer than $\sim 10 \mathrm{~ns}$, a task which can take a few weeks with a desk computer. So we have to be aware that only viscosities smaller than 100 Pa.s can be evaluated routinely by MD simulation, and for a MORB this viscosity range corresponds to a temperature higher than $1400 \mathrm{~K}$ (Shaw, 1969).

The MORB viscosity was evaluated in the temperature-pressure range $1673-3273 \mathrm{~K}$ and $0-40$ $\mathrm{GPa}$, respectively. The length of the simulation runs was about 10-30 ns in order to reach an accuracy better than $20 \%$. The evaluation of the viscosity consists in integrating over the time, the autocorrelation function of the stress tensor (Hess, 2002). This integral exhibits a S-shape (not shown) as function of the running time of the simulation, a shape which can be accurately fitted by a stretched exponential,

$\eta=\eta_{\infty}\left(1-e^{-\left(\frac{t}{\tau_{\text {relax }}}\right)^{\alpha}}\right)$

where $\eta_{\infty}$ is the final value of the viscosity when $\eta$ reaches a plateau value at long time, $\tau_{\text {relax }}$ is the shear relaxation time and $\alpha$ a coefficient $\leq 1$. In the T-P range investigated here $\alpha$ varies between 0.55 and 0.90 according to the temperature (higher the temperature, lower the viscosity, smaller the value of $\alpha$ ). Moreover, the shear modulus at infinite frequency, $G_{\infty}=\eta_{\infty} / \tau_{\text {relax }}$, deduced from the Maxwell relation, is found in the range $7-36 \mathrm{GPa}$ when $1673<\mathrm{T}<2273 \mathrm{~K}$ and in the range $36-100 \mathrm{GPa}$ when $2273<\mathrm{T}<3273 \mathrm{~K}$. The former values are in accordance with those estimated by Dingwell and Webb (1989) for various silicate melts near the glass transition temperature ( $\left.G_{\infty} \sim 3-30 \mathrm{GPa}\right)$. The evolution of the MORB viscosity (i.e. $\eta_{\infty}$ in Eq.(9)) with temperature is shown in Fig.6 and is compared with viscosity data of the literature. Although most of the experimental data for MORBs and related molten basalts are for temperatures lower than the presently investigated temperature range ( $\mathrm{T}$ $\geq 1673 \mathrm{~K}$ ), the overall agreement is excellent. In particular the calculated viscosity exhibits a nonArrhenian behavior with the temperature as expected for a basalt (Villeneuve et al., 2008). At our knowledge it is the first time that a MD simulation recovers quantitatively the viscosity data of a 
basaltic melt of natural composition near the liquidus (for comparison, in investigating by classical MD simulation the eutectic mixture $\mathrm{An}_{36} \mathrm{Di}_{64}$, a model basalt, Ben Martin et al. (2012) found for the viscosity of the simulated liquid a value twenty times smaller than the experimental one).

The evolution of the MORB viscosity with the pressure at constant temperature is reported in Fig.7. Our results reproduce very well the recent measurements made by Sakamaki et al. (2013) which show a small viscosity minimum near 3-4 GPa in the temperature range 1900-2000 K, a viscosity minimum still evoked by Ando et al. (2003). It is noteworthy that a viscosity minimum has also been reported in other silicate melts like in jadeite near 2-3 GPa in the T range 1700-2100 K (Suzuki et al., 2011), in the mixture diopside-jadeite (50/50 mol \%) at $3.5 \mathrm{GPa}$ and $2073 \mathrm{~K}$ (Suzuki et al., 2005), and in $\mathrm{Ca}_{3} \mathrm{Al}_{2} \mathrm{Si}_{6} \mathrm{O}_{18}$ melt at $3.7 \mathrm{GPa}$ in the T-range 1900-2000 K (Allwardt et al., 2007). Moreover our calculations show that the viscosity minimum tends to shift at a higher pressure when the temperature increases but it disappears above $2273 \mathrm{~K}$. Another important result is that the MORB viscosity becomes very low (< $100 \mathrm{mPa} . \mathrm{s})$ when $\mathrm{T}>2273 \mathrm{~K}$. The important point is not that the viscosity is low because the temperature is high but that it remains low even at 30 or $40 \mathrm{GPa}$ (see Fig.7). This finding could have some implications concerning the geodynamics of the Archean mantle of the ancient Earth.

\subsection{Electrical conductivity and ionic diffusion.}

The electrical conductivity is an important transport property because it gives a direct information on the mobility of the elements in the melt (the ionic transport is considered as responsible of the electrical conductivity in silicate melts, other mechanisms such as electronic conduction being negligible) and is a key parameter to interpret data collected from magnetotelluric soundings of the Earth's mantle (Pommier, 2014). The electrical conductivity was calculated from the Green-Kubo relation (Hansen and McDonald, 1986),

$\sigma=\frac{1}{k_{B} T V} \lim _{t \rightarrow \infty} \frac{1}{6 t}<\left|\sum_{i=1}^{N} z_{i}\left(\vec{r}_{i}(t)-\vec{r}_{i}(0)\right)\right|^{2}>$

where $k_{B}$ is the Boltzmann constant, $T$ the temperature, $V$ the volume of the sample, $z_{i}$ the electric charge of ion $i, \vec{r}_{i}(t)$ its position at time $t$, and where the angular brackets express an average taken over many time origins. The evaluation of the conductivity from the above relation is reliable as long 
as the diffusive regime is reached, that is when the mean square displacement of the ionic charges follows a straight line of slope equal to one in a log-log representation. In practice, the diffusive regime is reached after a few ps at high temperature $(\mathrm{T}>2273 \mathrm{~K})$ but only after several hundreds of picoseconds at low temperature ( $\mathrm{T} \leq 1873 \mathrm{~K}$ ). The MD runs were long of $10 \mathrm{~ns}$ in order to reach an accuracy better than $10 \%$ on the electrical conductivity.

Before to present the results it is noteworthy that the evaluation by Eq.(10) is relevant as far as the charges $z_{i}$ of the ions are well defined. In the case of a molten salt as $\mathrm{NaCl}$, which is fully ionic, the charges assigned to $\mathrm{Na}$ and $\mathrm{Cl}$ are the formal charges $+1 \mathrm{e}$ and $-1 \mathrm{e}$, respectively (Guillot and Guissani, 1994). The situation is different with silicate melts. As a matter of fact, the interactions between the elements of the melt are partially ionic and partially covalent with strong polarization effects. Therefore, the effective electric charge is smaller than the formal charge prescribed by chemistry. The empirical force fields of the literature, which are based upon a rigid ion model (i.e. without ionic polarizability), have effective charges which are roughly half of the formal charges (i.e. $z_{o} \sim-1 \mathrm{e}$ instead of $-2 \mathrm{e}$, the charges of the cations being deduced from the electroneutrality of the corresponding metal oxides). For instance, the effective charges associated with the TTAM and BKS potentials for silica (Tsuneyuki et al., 1988; van Beest et al., 1990), which are fitted on Hartree-Fock calculations of $\mathrm{SiO}_{4}$ clusters, amount to $z_{O}=-z_{S i} / 2=-1.2 \mathrm{e}$. Other approaches, based on a minimization procedure (force matching or structure matching) between a DFT calculation and a MD simulation, also lead to a reduced value for the oxygen charge in liquid silica (-0.955e by Carré et al., 2008; -0.90 e by Beck et al., 2012), in liquid magnesia (-1.1e by Beck et al., 2012), and in liquid alumina (-0.83e by Beck et al., 2012). Therefore, and for the sake of consistency, we have introduced in Eq.(10) the effective charges implemented in our force field (i.e. $z_{\mathrm{O}}=-0.945 \mathrm{e}, z_{\mathrm{Si}}=+1.89 \mathrm{e}, .$. ). However, we have to keep in mind that the ionic charges actually involved in the electrical conductivity of silicate melts could be slightly different from the ones implemented in our calculations.

In Fig.8, our MD calculations are compared with some conductivity data for tholeiitic and related melts. The overall agreement is quite satisfying in considering the various sources of experimental uncertainties as the differences in the melt composition, the degree of crystallinity (Presnall et al., 1972; Gaillard and Iacono-Marziano, 2005), or the redox conditions during the conductivity 
measurements (Pommier et al., 2010; Malki et al., 2015). However, the calculated values seem to underestimate a little the conductivity of melts investigated by Presnall et al. (1972), Waff and Weill (1975) and Tyburczy and Waff (1983) ( 10 S/m at $1673 \mathrm{~K}$ instead of $\sim 3-4 \mathrm{~S} / \mathrm{m}$ by simulation) whereas the data of Gaillard and Marziano (2005), Pommier et al. (2010) and those of Ni et al. (2011) are rather well reproduced. The pressure dependence of the conductivity of silicate melts is poorly known and is limited to a few GPa at most (see Maumus et al., 2005, Dai et al., 2015, and references therein). Thus, Tyburczy and Waff (1983) found a small decrease of the conductivity of a Hawaian tholeiite melt at $1473-1673 \mathrm{~K}$ when the pressure is increased from ambient to $1.8 \mathrm{GPa}$. Our results are compatible with this finding (see the pressure behavior along the isotherms $1673 \mathrm{~K}$ and $1873 \mathrm{~K}$ in Fig.9). An interesting prediction is that the evolution of the conductivity with the pressure depends on the temperature. Thus the conductivity of the simulated MORB is negatively correlated with the pressure for temperatures smaller than $\sim 2073 \mathrm{~K}$ and it becomes constant or positively correlated with it at higher temperature. More precisely, in the temperature range 2073-2273 K the conductivity is mostly constant whereas at $2673 \mathrm{~K}$ it increases gradually with the pressure before to reach a maximum value (at about $\sim 20 \mathrm{GPa}$, see Fig.9). This behavior is at variance with common wisdom that a high pressure must inhibit the mobility of charge carriers. We will see in the following that this feature is the result of a complex behavior with $\mathrm{P}$ and $\mathrm{T}$ of the diffusivity of charge carriers.

To relate the electrical conductivity with the diffusion of the charge carriers, it is usual to start from the Nernst-Einstein relation,

$\sigma_{N E}=\frac{1}{k_{B} T V} \sum_{i=1}^{n_{s}} N_{i} z_{i}^{2} D_{i}$

where $k_{B}$ is the Boltzmann constant, $T$ the temperature, $V$ the volume of the sample, $n_{s}$ the number of ionic species, $N_{i}$ the number of ions of species $i, z_{i}$ the electric charge of ion $i$, and $D_{i}$ the self-diffusion coefficient of ion $i$. This relation assumes that, (1) the ion-ion cross correlations are negligible (in introducing this assumption in Eq.(10), the Eq.(11) is recovered, see hereafter), and (2) the charge carried by the ion $i$ is equal to its formal value. These two assumptions being questionable, Eq.(11) is in general used with a correcting factor, named the Haven ratio $\left(H_{R}\right)$, such as the measured electrical conductivity is related to $\sigma_{N E}$ by the expression, 
$\sigma=H_{R} \cdot \sigma_{N E}$

where $\sigma$ is the electrical conductivity of the melt. Note that in the literature $H_{R}$ is generally expressed as $H_{R}^{-1}$ in Eq.(12) and is of the order of $\sim 1-5$ in simple silicate melts. From Eq.(10) it is possible to derive a formal expression of the Haven ratio (for an alternative derivation see Kashyap et al., 2011),

$H_{R}=1+\frac{\sum_{i=1}^{n_{S}} N_{i}\left(N_{i}-1\right) z_{i}^{2} H_{i}+\sum_{i=1}^{n_{S}} \sum_{j=1}^{n_{S}} N_{i} N_{j} z_{i} z_{j} H_{i j}}{\sum_{i=1}^{n_{S}} N_{i} z_{i}^{2} D_{i}}$

with

$H_{i}=\lim _{t \rightarrow \infty} \frac{1}{N_{i}\left(N_{i}-1\right)} \sum_{l=1}^{N_{i}} \sum_{m \neq l}^{N_{i}}<\left(\vec{r}_{l}(t)-\vec{r}_{l}(0)\right) \cdot\left(\vec{r}_{m}(t)-\vec{r}_{m}(0)\right)>$

$H_{i j}=\lim _{t \rightarrow \infty} \frac{1}{N_{i} N_{j}} \sum_{l=1}^{N_{i}} \sum_{m=1}^{N_{j}}<\left(\vec{r}_{l}(t)-\vec{r}_{l}(0)\right) \cdot\left(\vec{r}_{m}(t)-\vec{r}_{m}(0)\right)>$

where $N_{i}$ is the number of ions of species $i, n_{s}$ the number of ionic species, $\vec{r}_{l}(t)$ the position at time $t$ of ion $l$, and where the angular brackets express an average over many time origins. Notice that $H_{i}$ expresses the cross correlations between the displacements of one atom of species $i$ with those of another atom of the same species, whereas $H_{i j}$ expresses the cross correlations between the displacements of an atom of species $i$ with those of an atom of another species $j$. Furthermore, by definition (see Eq.(13)), $H_{R}$ is independent of the magnitude of the charge assigned to the ions (as long as effective charges can be defined).

In using Eqs.(11) and (12), several studies (Tiburczy and Waff, 1983, 1985; Gaillard, 2004; Pommier et al., 2008, 2010) have identified sodium as the main charge carrier governing the conductivity of natural (sodium bearing) silicate melts at temperature near the liquidus. For instance, Pommier et al. (2010) emphasized that sodium contributes for $80 \%$ to the bulk conductivity of a Kilauea basalt at $1573 \mathrm{~K}(11 \%$ for K, 3-4 \% for $\mathrm{Ca}$ and $\mathrm{O}$, and less than $1 \%$ for $\mathrm{Mg}, \mathrm{Si}$ and $\mathrm{Al})$. But this evaluation is only approximate because the uncertainties on the self-diffusion coefficients are large (for a review see Lesher, 2010), and the ionic charges carried by the elements are assumed to be equal to the formal ones. Actually, at high temperature, the interpretation of the bulk conductivity in terms of only one charge carrier (e.g. $\mathrm{Na}$ ) is misleading because $H_{R}$ expresses the cross correlations between all ions into the melt (see Eqs.(13)-(15)). A different situation occurs at low temperature near 
the glass transition temperature where a decoupling between the motions of light elements (e.g. Na) and those of network formers takes place (Gruener et al., 2001).

In this context the MD simulation has a great advantage since it is possible to evaluate in the same numerical experiment at once, the electrical conductivity, the self-diffusion coefficients of the elements and hence, the Nernst-Einstein conductivity and the Haven ratio. The self-diffusion coefficients were evaluated from the mean square displacements (MSD) of the atoms,

$D_{S}=\lim _{t \rightarrow \infty} \frac{1}{N_{S}} \sum_{i=1}^{N_{S}} \frac{\left\langle\left(\vec{r}_{i}(t)-\vec{r}_{i}(0)\right)^{2}>\right.}{6 t}$

where $N_{s}$ is the number of atoms of species $s, \vec{r}_{i}(t)$ the position at time $t$ of ion $i$, and where the angular brackets express an average taken over many time origins. The diffusive regime is reached when the time evolution of the MSD described a straight line of slope equal to one in a $\log (\mathrm{MSD})$ versus $\log (t)$ representation. In the present case the simulation runs were long enough (>10 ns) to insure that the diffusive regime was reached whatever the thermodynamic conditions under investigation. The accuracy on $D_{s}$ is generally better than $10 \%$, except for the potassium cation, for which the low concentration leads to a larger statistical uncertainty $(\sim 30 \%)$. In Fig.10 are shown in an Arrhenius diagram the temperature dependence of the self-diffusion coefficients in the MORB melt at atmospheric pressure. As reported, $\mathrm{Na}$ is the most mobile ion whereas the network formers $(\mathrm{O}, \mathrm{Si}, \mathrm{Al}$, and Ti) are the least mobile elements. Furthermore, the lower the magnitude of $D_{s}$ the higher the corresponding activation energy (from $\sim 140 \mathrm{~kJ} / \mathrm{mol}$ for $\mathrm{Na}$ to $\sim 180 \mathrm{~kJ} / \mathrm{mol}$ for $\mathrm{Si}$ ), a correlation termed compensation law (Winchell, 1969; Hofmann, 1980) implying that at some (very) high temperature the $D$ 's of all elements in the liquid converge towards a common value. A comparison with diffusion data for $\mathrm{Si}, \mathrm{O}, \mathrm{Na}, \mathrm{Mg}, \mathrm{Ca}, \mathrm{Fe}$, and Ti in basaltic melts is also shown in Fig.10. The agreement is quite remarkable in considering all sources of uncertainties and particularly the differences in melt composition. The only point of disagreement is that the simulation predicts for $\mathrm{Si}$ a diffusion coefficient lower than that of O whereas Lesher et al. (1996) reported close values in a basaltic liquid. Nevertheless, the difference between $D_{O}$ and $D_{S i}$ that we obtain in the MD calculation (a ratio of $\sim 5$ 1.5, which decreases when $\mathrm{T}$ and/or $\mathrm{P}$ increase) is comparable to the one observed in diopsideanorthite melt (Tinker et al., 2003) and in dacitic liquid (Tinker and Lesher, 2001), for instance. 
With regard to the pressure dependence of the self-diffusion coefficients in basaltic melts and in related compositions, data are scarce (Lesher, 2010) and mostly restricted to O and Si for pressures up to a few GPa (e.g. Lesher et al., 1996; Tinker et al., 2003). In Fig.11 are reported the simulation data. One notices that the self-diffusion of network modifiers decreases significantly when the pressure increases, whereas that of the network formers $(\mathrm{O}, \mathrm{Si}, \mathrm{Al}$ and $\mathrm{Ti})$ is more subtle as it decreases with $\mathrm{P}$ at $1673 \mathrm{~K}$, when it increases with $\mathrm{P}$ at $2073 \mathrm{~K}$ (the situation at $1873 \mathrm{~K}$ is intermediate with a slight maximum exhibited by $\mathrm{Si}$ and $\mathrm{O}$ at about $3 \mathrm{GPa}$, not shown). This behavior is in agreement with $\mathrm{O}$ and Si diffusivity data (Tinker et al., 2003) in a basaltic melt at $\mathrm{T}=1950-2000 \mathrm{~K}$ showing a gradual increase of $D_{S i}$ and $D_{O}$ with $\mathrm{P}$ in the pressure range $1-4 \mathrm{GPa}$ (see Fig.11 for a comparison). A positive correlation between the diffusion of network formers and the pressure is also observed with more polymerized melts like jadeite (Shimizu and Kushiro, 1984), dacite (Tinker and Lesher, 2001), albite (Poe et al., 1997), and sodosilicates (Rubie et al., 1993) and even a maximum in oxygen diffusivity is reached at high pressure with aluminosilicate compositions (Poe et al., 1997). In contrast, a negative correlation with the pressure followed by a minimum in $\mathrm{Si}$ and $\mathrm{O}$ diffusivities is observed in liquid diopside (Shimizu and Kushiro, 1984; Reid et al., 2001), a depolymerized melt. So our simulation data suggest that the pressure behavior of the diffusion of network formers in a MORB melt is quite similar to the one observed in more polymerized melts. As for the network modifiers, the rare experimental studies under pressure dealing mostly with intermediate compositions show that the diffusion of $\mathrm{Ca}$ and $\mathrm{Mg}$ is negatively correlated to the pressure (Watson, 1979; Shimizu and Kushiro, 1984), a behavior that it is observed in our results. Furthermore, an interesting prediction is that $\mathrm{Ti}$, $\mathrm{Fe}^{3+}$ and $\mathrm{Fe}^{2+}$ make themselves conspicuous among the other network modifiers as they exhibit a maximum of diffusivity with the pressure (see the maximum at $1 \mathrm{GPa}$ and $2073 \mathrm{~K}$ in Fig.11).

In introducing the values of the self-diffusion coefficients into the definition of the Nernst-Einstein conductivity (Eq.(11)), it is easy to evaluate the Haven ratio from Eq.(12). The results are presented in Fig.12. On average $H_{R}$ amounts to $\sim 3.7$ but with a rather large dispersion $\left(H_{R}^{\max }=5.6\right.$ and $H_{R}^{\min }=$ 2.5) according to the thermodynamic conditions (e.g. 1673 - $2073 \mathrm{~K}$ and 0 - $12 \mathrm{GPa}$ ). More precisely, $H_{R}$ decreases when $\mathrm{T}$ or $\mathrm{P}$ increases. The finding that $H_{R}$ is (much) greater than one means that the ionic motions are cooperative. Thus the repulsion between charge carriers of the same sign tends to 
increase the conductivity (see also Kashyap et al., 2011). As a matter of fact, after a rapid look at Eqs.(12)-(14) it can be stated that if the ions behaved independently from each other in the melt, then $H_{R}=1$ (and $\sigma=\sigma_{N E}$ ), and if the ionic motions were slow down by the anion-cation correlations (the ionic dissociation becoming less effective) then the conductivity would be smaller than predicted by the NE relation $\left(H_{R}<1\right)$. For instance, the latter situation occurs in molten calcium carbonate, a molten salt for which $H_{R} \sim 0.8$ (Vuilleumier et al., 2014). In this context it is questionable (or unnecessary) to disentangle from the total conductivity the respective contributions of charge carriers (Harris, 2010). In spite of that, and for convenience, it is usual to decompose the total conductivity in a sum of effective individual conductivities (e.g. Pommier et al., 2008; Malki et al., 2015),

$\sigma=\sum_{i=1}^{n_{S}} \sigma_{i}=\sum_{i=1}^{n_{S}} H_{R} \frac{D_{i} z_{i}^{2} N_{i}}{k_{B} T V}$

where $\sigma_{i}$ is the effective conductivity associated with the charge carrier $i$. The individual contributions $\left(\sigma_{i} / \sigma\right)$ to the melt conductivity at $1673 \mathrm{~K}$ and atmospheric pressure are the following (in percent): $\mathrm{O}=$ 24.3, $\mathrm{Na}=21.1, \mathrm{Mg}=16.0, \mathrm{Ca}=13.2, \mathrm{Al}=12.9, \mathrm{Si}=5.9, \mathrm{Fe}^{2+}=5.2, \mathrm{Fe}^{3+}=0.6, \mathrm{~K}=0.4$, and $\mathrm{Ti}=$ 0.3. So in a MORB melt at $1673 \mathrm{~K}$, sodium is not driving alone the conductivity since the contribution of other network modifiers is about $35 \%$ whereas the one coming from the network formers is as high as $43 \%$ of the whole. However, near the glass transition temperature, the contribution of the sodium ion to the conductivity is expected to be overwhelming (despite its low concentration) because its excess of mobility with respect to that of the other charge carriers (except K) increases very rapidly when the temperature decreases (see Fig.10). Correlatively the sodium contribution decreases when the temperature increases (from $\sim 21 \%$ at $1673 \mathrm{~K}$ to $\sim 12 \%$ at $2073 \mathrm{~K}$ and $\mathrm{P}=0 \mathrm{GPa}$ ) and diminishes when the pressure is increased (e.g. at $2073 \mathrm{~K}, 12 \%$ at $0 \mathrm{GPa}, 8 \%$ at $1 \mathrm{GPa}, 3 \%$ at $5 \mathrm{GPa}$, and $\sim 1 \%$ at $12 \mathrm{GPa}$ ). As for the contributions of $\mathrm{Ca}, \mathrm{Mg}, \mathrm{Fe}^{2+}$, and $\mathrm{Fe}^{3+}$, their evolutions with temperature and pressure are non-monotonous (for instance the contributions of $\mathrm{Ca}$ and $\mathrm{Mg}$ go through a slight minimum with $\mathrm{T}$ and a slight maximum with $\mathrm{P}$ ). In contrast, the contributions of $\mathrm{O}, \mathrm{Si}$ and $\mathrm{Al}$ are positively correlated both with $\mathrm{T}$ and $\mathrm{P}$. An interesting result is that the electrical conductivity of a MORB melt at depth in the oceanic mantle is controlled for the most part by the mobility of network 
formers (e.g. at $1873 \mathrm{~K}$ and $5 \mathrm{GPa}, \mathrm{O}=32.7, \mathrm{Si}=20, \mathrm{Al}=15.4, \mathrm{Mg}=12.4, \mathrm{Ca}=7.6, \mathrm{Fe}^{2+}=5.1, \mathrm{Na}=$ $4.8, \mathrm{Fe}^{3+}=1.5, \mathrm{Ti}=0.5$, and $\left.\mathrm{K} \sim 0.1 \%\right)$.

\section{Concluding remarks}

The simulation data presented here could be useful to quantify some scenarios concerning the geodynamics of the Earth's mantle. For instance, the evolution of the MORB density with $\mathrm{P}$ and T suggests that the melt is always buoyant with respect to the PREM density profile (Dziewonski and Anderson, 1981) whereas the melt density is lower than that of the perovskite phase which crystallizes at conditions of the uppermost lower mantle. Moreover, the EOS of this perovskite phase suggests a possible scenario where a subducted oceanic plate is sinking deep into the mantle because its density is always higher than PREM for the present geotherm. However, the finding that the density of the perovskite phase intersects the PREM density profile at $50 \mathrm{GPa}$ and $2600 \mathrm{~K}$ (see Fig.2) lead us to speculate that during the Archean era when the mantle temperature was higher (with a potential temperature $\mathrm{T}_{\mathrm{p}} \sim 1750 \mathrm{C}$ instead of $\sim 1350 \mathrm{C}$, after Herzberg et al. (2010)) the density of a subducted oceanic plate could match or be smaller than the density of the ambient mantle and hence would be stagnant or buoyant. Of course this may happen only if the density profile of the Archean mantle and the PREM's one are alike. This might be the case since the composition of the lower mantle being richer in $\mathrm{Mg}$ and $\mathrm{Fe}$ than a MORB, its compressibility is lesser and the effect of a higher temperature on the mantle density profile is weaker.

Concerning the MORB transport properties, our calculations show that the viscosity becomes really low (i.e. $<100 \mathrm{mPa} . \mathrm{s}$ ) at high temperature (above $2273 \mathrm{~K}$ ) and whatever the pressure is. This feature could have played a role during the Archean to separate rapidly a buoyant magma from its solid matrix. As a matter of fact, the hydrostatic magma mobility (gravity driven) is proportional to $\sim \Delta n / \eta$, where $\Delta n$ is the difference in density between the magma and the surrounding solid rock and $\eta$ the 
melt viscosity (Connolly et al., 2009). Thus the mobility of a hypothetical basaltic melt generated at $2600 \mathrm{~K}$ and $25 \mathrm{GPa}$ (e.g. a melt issued from the interaction between a subducted oceanic plate and a hot mantle plume) is roughly two orders of magnitude higher than the one of an incipient melt generated at $30 \mathrm{~km}$ under an oceanic ridge (according to Fig.7, $\eta \sim 50 \mathrm{mPa} . \mathrm{s}$ at $2600 \mathrm{~K}$ and $25 \mathrm{GPa}$ instead of $\sim 3$ Pa.s at $1673 \mathrm{~K}$ and $1 \mathrm{GPa})$.

The simulation data give some clues concerning the relationship between viscosity and electrical conductivity, a relationship which, among other things, can be useful to improve the interpretation of magnetotelluric data (Pommier et al., 2013). Because the self-diffusion coefficients of the ions in the melt increase with the temperature, the viscosity is negatively correlated with the temperature when the electrical conductivity is positively correlated to it. Therefore, one recovers the well-known result that, at a given pressure, $\eta$ and $\sigma$ are negatively correlated with each other (Pfeiffer, 1998; Harris, 2010; Pommier et al., 2013). However, the quantification of this correlation with the help of an analytical expression is difficult for silicate melts because the viscosity is mainly governed by the least mobile ions (network formers) whereas the electrical conductivity is governed by the most mobile ones (network modifiers). Furthermore, at low temperatures (near the glass transition temperature) the diffusion motions of the network formers and those of network modifiers are essentially decoupled from each other (their self-diffusion coefficients differ by orders of magnitude) whereas at high temperature- high pressure their diffusion motions are practically of the same order of magnitude (see Fig.11). The net result is that the product $\eta \times \sigma$ is not a simple function of the temperature and pressure as illustrated in Fig.13. This product exhibits a rapid decay quasi linear with T between 1673 and $2073 \mathrm{~K}$ followed by a sudden change of slope leading to a quasi-stationary behavior at higher T. Moreover, the magnitude of the product $\eta \times \sigma$ decreases strongly when $\mathrm{P}$ decreases from 0 to $\sim 3 \mathrm{GPa}$ whereas it remains quasi constant up to $15 \mathrm{GPa}(\eta \times \sigma \sim 1-2)$ in the T-range $2073-2673 \mathrm{~K}$ or exhibits a gradual increase with $\mathrm{T}$ at higher pressure. It is noteworthy that the change of slope at about $2073 \mathrm{~K}$ corresponds approximately to the temperature range where the self-diffusion coefficients of the most mobile ions and those of the least mobile ions differ by less than two orders of magnitude, a finding which suggests that virtually all ions are contributing to $\eta$ and $\sigma$. Thus above $2073 \mathrm{~K}$ the product $\eta \times \sigma$ evolves weakly with $\mathrm{T}$ and $\mathrm{P}$ (that is, $\eta \propto 1 / \sigma$ ), a behavior also observed with a molten salt like 
$\mathrm{CaCO}_{3}$ for instance (Vuilleumier et al., 2014) because the mobility of the charge carriers (i.e. $\mathrm{Ca}^{2+}$ and $\mathrm{CO}_{3}{ }^{2-}$ ) are of the same order of magnitude.

\section{Acknowledgements}

The research leading to these results has received funding from the Agence Nationale pour la Recherche (under Grant agreement ANR-2010-BLAN-621-03), and the European Community's Seventh Framework Programme (FP7/2007-2013) under Grant agreement (ERC, N²79790).

\section{Bibliography}

Agee C.B. (1998) Crystal-liquid density inversions in terrestrial and lunar magmas. Phys. Earth Planet. Int. 107, 63-74.

Alderman O.L.G., Skinner L.B., Benmore C.J., Tamalonis, A. and Weber J.K.R. (2014) Structure of molten titanium dioxide. Phys. Rev. B 90, 094204-1-13.

Allen M.P. and Tildesley D.J. (1987) Computer simulation of liquids. Oxford Science Publications, Clarendon Press.

Allwardt J.R., Stebbins J.F., Terasaki H., Du L-S, Frost D.J., Withers A.C., Hirschmann M.M., Suzuki A. and Ohtani E. (2007) Effect of structural transitions on properties of high-pressure silicate melts: ${ }^{27} \mathrm{Al}$ NMR, glass densities, and melt viscosities. Am. Mineral. 92, 1093-1104.

Ando R., Ohtani E., Suzuki A., Rubie D.C. and Funakoshi K. (2003) Pressure dependency of viscosities of MORB melts. AGU Fall meeting, abstract \#V31D-0958.

Andrault D., Pesce G., Bouhifd M.A., Bolfan-Casanova N., Hénot J.-M. and Mezouar M. (2014) Melting of subducted basalt at the core-mantle boundary. Science 344, 892-895.

Angell C.A., Cheeseman P.A. and Kadiyala R.R. (1987) Diffusivity and thermodynamic properties of diopside and jadeite melts by computer simulation studies. Chem. Geol. 62, 83-91.

Bajgain S., Ghosh D.B. and Karki B.B. (2015) Structure and density of basaltic melts at mantle conditions from first-principles simulations. Nature communications 6, 8578-1-7. 
Bauchy M., Guillot B., Micoulaut M. and Sator N. (2013) Viscosity and viscosity anomalies of model silicates and magmas: a numerical investigation. Chem. Geol. 346, 47-56.

Beck Ph., Brommer P., Roth J. and Trebin H.-R. (2012) Influence of polarizability on metal oxide properties studied by molecular dynamics simulations. J. Phys.: Condens. Matter 24, 485401-1-8.

Belmonte D., Ottonello G. and Vetuschi Zuccolini M. (2014) Ab initio thermodynamic and thermophysical properties of sapphirine end-members in the join $\mathrm{Mg}_{4} \mathrm{Al}_{8} \mathrm{Si}_{2} \mathrm{O}_{20}-\mathrm{Mg}_{3} \mathrm{Al}_{10} \mathrm{SiO}_{20}$. Am. Mineral. 99, 1449-1461.

Ben Martin G., Ghiorso M. and Spera F.J. (2012) Transport properties and equation of state of 1-bar eutectic melt in the system $\mathrm{CaAl}_{2} \mathrm{Si}_{2} \mathrm{O}_{8}-\mathrm{CaMgSi}_{2} \mathrm{O}_{6}$ by molecular dynamics simulation. Am. Mineral. 97, 1155-1164.

Benmore C.J., Weber J.K.R., Wilding M.C., Du J. and Parise J.B. (2010) Temperature-dependent structural heterogeneity in calcium silicate liquids. Phys. Rev. B 82, 224202-1-6.

Brown Jr., G.E., Farges F. and Calas G. (1995) X-ray scattering and X-ray spectroscopy studies of silicate melts. Rev. Mineral. 32, 317-410.

Carré A., Horbach J., Ispas S. and Kob W. (2008) New fitting scheme to obtain effective potential from Car-Parrinello molecular-dynamics simulations: Application to silica. Eur. Phys. Lett. 82, 17001$1-6$.

Connolly J.A.D., Schmidt M.W., Solferino G. and Bagdassarov N. (2009) Permeability of asthenospheric mantle and melt extraction rates at mid-ocean ridges. Nature 462, 209-212.

Courtial P. and Dingwell D.B. (1999) Densities of melts in the $\mathrm{CaO}-\mathrm{MgO}-\mathrm{Al}_{2} \mathrm{O}_{3}-\mathrm{SiO}_{2}$ system. Am. Mineral. 84, 465-476.

Crépisson C., Morard G., Bureau H., Prouteau G., Morizet Y., Petitgirard S. and Sanloup C. (2014). Magmas trapped at the continental lithosphere-asthenosphere boundary. Earth and Planet. Sci. Lett. 394, 105-112.

Cristiglio V., Cuello G.J., Hennet L., Pozdnyakov I., Leydier M., Kozaily J., Fischer H.E., Johnson M.R. and Price D.L. (2010) Neutron diffraction study of molten calcium aluminates. J. Non-Cryst. Solids 44-49, 2492-2496. 
Dai L., Jiang J., Li H., Hu H. and Hui K. (2015) Electrical conductivity of hydrous natural basalts at high temperatures and pressures. J. Applied Geophys. 112, 290-297.

Dingwell D.B. and S.L. Webb (1989) Structural relaxation in silicate melts and non-Newtonian melt rheology in geologic processes. Phys. Chem. Minerals 16, 508-516.

Drewitt J.W.E., Sanloup C., Bytchkov A., Brassamin S. and Hennet L. (2013) Structure of $\left(\mathrm{Fe}_{\mathrm{x}} \mathrm{Ca}_{1-}\right.$ х) $y\left(\mathrm{SiO}_{2}\right)_{1-y}$ liquids and glasses from high-energy x-ray diffraction: Implications for the structure of natural basaltic magmas. Phys. Rev. B 87, 224201-1-10.

Dziewonski A.M. and Anderson D.L. (1981) Preliminary reference Earth model. Phys. Earth Planet. Int. 25, 297-356.

Eiler J. ed (2003) Inside the subduction factory, vol.138, AGU, Washington, DC, 311 pp.

Funamori N., Yamamoto, Yagi T. and Kikegawa T. (2004) Exploratory studies of silicate melt structure at high pressures and temperatures by in situ X-ray diffraction. J. Geophys. Res. 109, B03203-1-8

Gaillard F. (2004) Laboratory measurements of electrical conductivity of hydrous and dry silicic melts under pressure. Earth and Planet. Sci. Lett. 218, 215-228.

Gaillard F. and Iacono-Marziano G. (2005) Electrical conductivity of magma in the course of crystallization controlled by their residual liquid composition. J. Geophys. Res. 110, B06204-1-12.

Grimes N.W. and Grimes R.W. (1998) Dielectric polarizability. of ions and the corresponding effective number of electrons. J. Phys.: Condens. Matter 10, 3029-3034.

Gruener G., Odier P., De Sousa Meneses D., Florian P. and Richet P. (2001) Bulk and local dynamics in glass-forming liquids: A viscosity, electrical conductivity, and NMR study of aluminosilicate melts. Phys. Rev. B 64, 024206-1-5.

Guillot B. and Guissani Y. (1994) Coexisting phases and criticality in $\mathrm{NaCl}$ by computer simulation. J. Chem. Phys. 101, 490-509. 
Guillot B. and Sator N. (2007a) A computer simulation study of natural silicate melts. Part I: Low pressure properties. Geochim. Cosmochim. Acta 71, 1249-1265.

Guillot B. and Sator N. (2007b) A computer simulation study of natural silicate melts. Part II: High pressure properties. Geochim. Cosmochim. Acta 71, 4538-4556.

Hansen J.P. and McDonald I.R. (1986) Theory of simple liquids, London, Academic Press, Chapter 10.

Harris K.R. (2010). Relations between the fractional Stokes-Einstein and Nernst-Einstein equations and velocity correlation coefficients in ionic liquids and molten salts. J. Phys. Chem. B 114, 95729577.

Heaton R.J., Madden P.A., Clark S.J. and Jahn S. (2006) Condensed phase ionic polarizabilities from plane wave density functional theory calculations. J. Chem. Phys. 125, 144104-1-10.

Herzberg C., Condie K. and Korenaga J. (2010) Thermal history of the Earth and its petrological expression, Earth Planet. Sci. Lett. 292, 79-88.

Hess B. (2002). Determining the shear viscosity of model liquids from molecular dynamics simulations. J. Chem. Phys. 116, 209-217.

Hirose K., Fei Y., Ma Y. and Mao H-K (1999) The fate of subducted basaltic crust in the Earth's lower mantle. Nature 397, 53-56.

Hirose K., Takafuji N., Sata N. and Ohishi Y. (2005) Phase transition and density of subducted MORB crust in the lower mantle. Earth and Planet. Sci. Lett. 237, 239-251.

Hofmann A.W. (1980) Diffusion in natural silicate melts: A critical review. In Physics of Magmatic processes, Hargraves RB (ed.) Princeton Univ. Press, Princeton, NJ, 385-417.

Kashyap H.K., Annapureddy H.V.R., Raineri F.O. and Margulis C.J. (2011) How is charge transport different in ionic liquids and electrolyte solutions? J. Phys. Chem. B 115, 13212-13221.

Karki B.B. (2015) First-principles computation of mantle materials in crystalline and amorphous phases. Phys. Earth and Planet. Int. 240, 43-69. 
Karki B.B. and Stixrude L.P. (2010) Viscosity of $\mathrm{MgSiO}_{3}$ liquid at Earth's mantle conditions: implications for an early magma ocean. Science 328, 740-742.

Klein E.M. and Langmuir C.H. (1987) Global correlations of ocean ridge basalt chemistry with axial depth and crustal thickness. J. Geophys. Res. 92, 8089-8115.

Koutselos A.D. and Mason E.A. (1986) Correlation and prediction of dispersion coefficients for isoelectronic systems. J. Chem. Phys. 85, 2154-2160.

Kushiro I., Yoder H.S., Jr., and Mysen B.O. (1976) Viscosity of basalt and andesite melts at high pressures. J. Geophys. Res. 81, 6351-6356.

Lacks D.J., Rear D.B., and Van Orman (2007) Molecular dynamics investigation of viscosity, chemical diffusivities and partial molar volume of liquids along the $\mathrm{MgO}-\mathrm{SiO}_{2}$ join as function of pressure. Geochim. Cosmochim. Acta 71, 1312-1323.

Lange R.A. and Carmichael I.S.E. (1987) Densities of $\mathrm{Na}_{2} \mathrm{O}-\mathrm{K}_{2} \mathrm{O}-\mathrm{CaO}-\mathrm{MgO}-\mathrm{FeO}-\mathrm{Fe}_{2} \mathrm{O}_{3}-\mathrm{Al}_{2} \mathrm{O}_{3}-\mathrm{TiO}_{2}-$ $\mathrm{SiO}_{2}$ liquids: new measurements and derived partial molar properties. Geochim. Cosmochim. Acta 51, 2931-2946.

Lasaga A.C. and Cygan R.T. (1982) Electronic and ionic polarizabilities of silicate minerals. Am. Mineral. 67, 328-334.

LaTourrette T., Wasserburg G.J. and Fahey A.J. (1996). Self diffusion of Mg, Ca, Ba, Nd, Yb, Ti, Zr, and $\mathrm{U}$ in haplobasaltic melt. Geochim. Cosmochim. Acta 60, 1329-1340.

Lee S.K., Cody G.D., Fei Y. and Mysen B.O. (2006) The effect of Na/Si ratio on the structure of sodium silicate and aluminosilicate glasses quenched from melts at high pressure: A multi-nuclear (Al-27, Na-23, O-17) 1D and 2D solid-state NMR study. Chem. Geol. 229, 162-172.

Lesher C.E. (2010) Self-diffusion in silicate melts: Theory, observations and applications to magmatic systems. Rev. Mineral. Geochem. 72, 269-309.

Lesher C.E., Hervig R.L. and Tinker D. (1996) Self diffusion of network formers (silicon and oxygen) in naturally occurring basaltic liquid. Geochim. Cosmochim. Acta 60, 405-413. 
Lowry R.K., Henderson P. and Nolan J. (1982) Tracer diffusion of some alkali, alkaline-Earth and transition element ions in a basaltic and an andesitic melt, and the implications concerning melt structure. Contrib. Mineral. Petrol. 80, 254-261.

Malki M., Magnien V., Pinet O. and Richet P. (2015) Electrical conductivity of iron-bearing silicate glasses and melts. Implications for the mechanisms of iron redox reactions. Geochim. Cosmochim. Acta 165, 137-147.

Matsui M. (1996) Molecular dynamics simulation of structures, bulk moduli, and volume thermal expansivities of silicate liquids in the system $\mathrm{CaO}-\mathrm{MgO}-\mathrm{Al}_{2} \mathrm{O}_{3}-\mathrm{SiO}_{2}$. Geophys. Res. Lett. 23, 395-398.

Maumus J., Bagdassarov and Schmeling H. (2005) Electrical conductivity and partial melting of mafic rocks under pressure. Geochim. Cosmochim. Acta 69, 4703-4718.

Murase T. and McBirney A.R. (1973) Properties of some common igneous rocks and their melts at high temperatures. Geol. Soc. Am. Bull. 84, 3563-3592.

Mysen, B.O. and Richet P., (2005) Silicate Glasses and Melts: Properties and Structure. Elsevier, Amsterdam.

Ni H., Keppler H. and Behrens H. (2011) Electrical conductivity of hydrous basaltic melts: implications for partial melting in the upper mantle. Contrib. Mineral. Petrol. 162, 637-650.

Ohtani E. (2009) Melting relations and the equation of state of magmas at high pressure: Application to geodynamics. Chem. Geol. 265, 279-288.

Ohtani E. and Maeda M. (2001) Density of basaltic melt at high pressure and stability of the melt at the base of the lower mantle. Earth and Planet. Sci. Lett. 193, 69-75.

Ono S., Ohishi Y., Isshiki M. and Watanuki T. (2005) In situ X-ray observations of phase assemblages in peridotite and basalt compositions of lower mantle conditions: Implications for density of subducted oceanic plate. J. Geophys. Res. 110, B02208-1-11.

Ottonello G., Attene M., Ameglio D., Belmonte D., Vetuschi Zuccolini M. and Natali M. (2013) Thermodynamic investigation of the $\mathrm{CaO}-\mathrm{Al}_{2} \mathrm{O}_{3}-\mathrm{SiO}_{2}$ system at high $\mathrm{P}$ and $\mathrm{T}$ through polymer chemistry and convex-hull techniques. Chem. Geol. 346, 81-92. 
Pelton A.D. and Blender M. (1986) Thermodynamic analysis of ordered liquid solutions by a modified quasi-chemical approach. Application to silicate slags. Metall. Trans. B 17, 805-815.

Pfeiffer T. (1998) Viscosity and electrical conductivities of oxidic glass-forming melts. Solid State Ionics 105, 277-287.

Plimpton S. (1995) Fast parallel algorithms for short-range molecular dynamics. J. Comp. Phys. 117, $1-19$.

Poe B.T., McMillan P.F., Rubie D.C., Chakraborty S., Yarger J. and Diefenbacher J. (1997) Silicon and oxygen self-diffusivities in silicate liquids measured to 15 gigapascals and 2800 Kelvin. Science 276, 1245-1248.

Pommier A. (2014) Interpretation of magnetotelluric results using laboratory measurements. Surv. Geophys. 35, 41-84.

Pommier A., Gaillard F., Pichavant M. and Scaillet B. (2008) Laboratory measurements of electrical conductivities of hydrous and dry Mount Vesuvius melts under pressure. J. Geophys. Res. 113, B05205-1-16.

Pommier A., Gaillard F. and Pichavant M. (2010) Time-dependent changes of the electrical conductivity of basaltic melts with redox state. Geochim. Cosmochim. Acta 74, 1653-1671.

Pommier A., Evans R.L., Key K., Tyburczy J.A., Mackwell S. and Elsebek J. (2013) Prediction of silicate melt viscosity from electrical conductivity: A model and its geophysical implications. Geochem. Geophys. Geosyst. 14, 1685-1692.

Pradhan G.K., Fiquet G., Siebert J., Auzende A.-L., Morard G., Antonangeli D. and Garbarino G. (2015) Melting of MORB at core-mantle boundary. Earth and Planet Sci. Lett. 431, 247-255.

Presnall D.C., Simmons C.L. and Porath H. (1972) Changes in electrical conductivity of a synthetic basalt during melting. J. Geophys. Res. 77, 5665-5672.

Reid J.E., Poe B.T., Rubie D.C., Zotov N. and Wiedenbeck M. (2001) The self-diffusion of silicon and oxygen in diopside $\left(\mathrm{CaMg}_{2} \mathrm{SiO}_{6}\right)$ liquid up to $15 \mathrm{GPa}$. Chem. Geol. 174, 77-86. 
Reynolds J.R. and Langmuir C.H. (1997) Petrological systematics of the Mid-Atlantic Ridge south of Kane: implications for ocean crust formation. J. Geophys. Res. 102, 14915-14946.

Ricolleau A., Perrillat J.-Ph., Fiquet G., Daniel I., Matas J., Addad A., Menguy N., Cardon H., Mezouar M. and Guignot N. (2010) Phase relations and equation of state of a natural MORB: Implications for the density profile of subducted oceanic crust in the Earth's lower mantle. J. Geophys. Res. 115, B08202-1-15.

Rubie D.C., Ross II C.R., Carroll M.R. and Elphick S.C. (1993). Oxygen self-diffusion in $\mathrm{Na}_{2} \mathrm{Si}_{4} \mathrm{O}_{9}$ liquid up to $10 \mathrm{GPa}$ and estimation of high-pressure melt viscosities. Am. Mineral. 78, 574-582.

Saal A.E., Hauri E.H., Langmuir C.H. and Perfit M.R. (2002) Vapour undersaturation in primitive mid-ocean-ridge basalt and the volatile content of Earth's upper mantle. Nature 419, 451-455.

Sakamaki T., Suzuki A., Ohtani E., Terasaki H., Urakawa S., Katayama Y., Funakoshi K-I, Wang Y., Hernlund J.W. and Ballmer M.D. (2013) Ponded melt at the boundary between the lithosphere and the asthenosphere. Nature Geoscience 6, 1041-1044.

Salanne M., Vuilleumier R., Madden P.A., Simon C., Turq P. and Guillot B. (2008) Polarizabilities of individual molecules and ions in liquids from first-principles. J. Phys.: Condens. Matter 20, 494207-18.

Sanderson R.T. (1983) Electronegativity and bond energy. J. Am. Chem. Soc. 105, 2259-2261.

Sanderson R.T. (1986) Electronegativity and bonding of transitional elements. Inorg. Chem. 25, 35183522.

Sanderson R.T. (1988) Principles of electronegativity. Part I. General nature. J. Chem. Educ. 65, 112118.

Sanloup C., Drewitt J.W.E., Konôpková, Dalladay-Simpson Ph., Morton D.M., Rai N., van Westrenen W. and Morgenroth W. (2013) Structural change in molten basalt at deep mantle conditions, Nature 503, 104-107.

Sato T. and Funamori N. (2010) High-pressure structural transformation of $\mathrm{SiO}_{2}$ glass up to $100 \mathrm{GPa}$. Phys. Rev. B 82, 184102-1-5. 
Scarfe C.M. (1973) Viscosity of basic magmas at varying pressure. Nature 241, 101-102.

Shaw H.R. (1969) Rheology of basalt in the melting range. J. Petrol. 10, 510-535.

Shannon R.D. (1993) Dielectric polarizabilities of ions in oxides and fluorides. J. Appl. Phys. 73, 348368.

Shannon R.D. and Fisher R.X. (2006) Empirical electronic polarizabilities in oxides, hydroxides, oxyfluorides, and oxychlorides. Phys. Rev. B 73, 235111-1-28.

Shimizu N. and Kushiro I. (1984) Diffusivity of oxygen in jadeite and diopside melts at high pressures. Geochim. Cosmochim. Acta 48, 1295-1303.

Skinner L.B., Benmore C.J., Weber J.K.R., Tumber S., Lazareva L., Neuefeind J., Santodonato L., Du J. and Parise J.B. (2012) Structure of molten $\mathrm{CaSiO}_{3}$ : Neutron diffraction isotope substitution with aerodynamic levitation and molecular dynamics study. J. Phys. Chem. B 116, 13439-13447.

Smith W. and Forester T. (1996). DL_Poly_2.0: a general-purpose parallel molecular dynamics simulation package. J. Mol. Graph. 14, 136-141.

Spera F.J., Ghiorso M.S. and Nevins D. (2011) Structure, thermodynamics and transport properties of liquid $\mathrm{MgSiO}_{3}$ : Comparison of molecular models and laboratory results. Geochim. Cosmochim. Acta 75, 1272-1296.

Stixrude L. and Karki B. (2005) Structure and freezing of $\mathrm{MgSiO}_{3}$ liquid in Earth's lower mantle. Science 310, 297-299.

Sun N., Stixrude L., de Koker N. and Karki B.B. (2011) First-principles molecular dynamics simulations of diopside $\left(\mathrm{CaMgSi}_{2} \mathrm{O}_{6}\right)$ liquid to high pressure. Geochim. Cosmochim. Acta 75, 37923802.

Suzuki A., Ohtani E., Terasaki H. and Funakoshi K.-I. (2005) Viscosity of silicate melts in $\mathrm{CaMgSi}_{2} \mathrm{O}_{6}-\mathrm{NaAlSi}_{2} \mathrm{O}_{6}$ system at high pressure. Phys. Chem. Minerals 32, 140-145.

Suzuki A., Ohtani E., Terasaki H., Nishida K., Hayashi H., Sakamaki T., Shibazaki Y. and Kikegawa T. (2011) Pressure and temperature dependence of the viscosity of a $\mathrm{NaAlSi}_{2} \mathrm{O}_{6}$ melt. Phys. Chem. Minerals 38, 59-64. 
Tinker D. and Lesher C.A. (2001) Self diffusion of Si and O in dacitic liquid at high pressures. Am. Mineral. 86, 1-13.

Tinker D., Lesher C.E. and Hutcheon I.D. (2003) Self-diffusion of Si and O in diopside-anorthite melt at high pressures. Geochim. Cosmochim. Acta 67, 133-142.

Tsuneyuki S., Tsukada M., Aoki H. and Matsui M. (1988). First principles interatomic potential of silica applied to molecular dynamics. Phys. Rev. Lett. 61, 869-872.

Tyburczy J.A. and Waff H.S. (1983) Electrical conductivity of molten basalt and andesite to 25 kilobars pressure: Geophysical significance and implications for charge transport and melt structure. J. Geophys. Res. 88, 2413-2430.

van Beest B.W.H., Kramer G.J. and Van Santen R.A. (1990). Force fields for silicas and aluminophosphates based on ab initio calculations. Phys. Rev. Lett. 64, 1955-1958.

Vercamer V., Lelong G., Hijiya H., Kondo Y., Galoisy L. and Calas G. (2015) Diluted Fe ${ }^{3+}$ in silicate glasses: Structural effects of Fe-redox state and matrix composition. An optical absorption and Xband/Q-band EPR study. J. Non-Cryst. Solids 428, 138-145.

Villeneuve N., Neuville D.R., Boivin P., Bachèrely P. and P. Richet (2008) Magma crystallization and viscosity: A study of molten basalts from the Piton de la Fournaise volcano (La Réunion island). Chem. Geol. 256, 242-251.

Vuilleumier R., Seitsonen A., Sator N. and Guillot B. (2014) Structure, equation of state and transport properties of molten calcium carbonate $\left(\mathrm{CaCO}_{3}\right)$ by atomistic simulations. Geochim. Cosmochim. Acta. 141, 547-566.

Waasmeier D. and Kirfel A. (1995) New analytical scattering-factor functions for free atoms and ions. Acta Crystallogr. A51, 416-431.

Waff H.S. and Weill D.F. (1975) Electrical conductivity of magmatic liquids: Effects of temperature, oxygen fugacity, and composition. Earth Planet Sci. Lett. 28, 254-260.

Watson E.B. (1979) Calcium diffusion in a simple silicate melt to 30 kbar. Geochim. Cosmochim. Acta 43, 313-322. 
Wilding M.C., Benmore C.J. and Weber J.K.R. (2010) Changes in the local environment surrounding magnesium ions in fragile $\mathrm{MgO}-\mathrm{SiO}_{2}$ liquids. Europhys. Lett. 89, 26005-1-2.

Winchell P (1969) The compensation law for diffusion in silicates. High Temp. Sci. 1, 200-215.

Xue X., Stebbins J.F., Kanzaki M., McMillan P.F. and Poe B. (1991) Pressure induced silicon coordination and tetrahedral structural changes in alkali oxide-silica melts up to 12 GPa: NMR, Raman and infrared spectroscopy. Am. Mineral. 76, 8-26.

Zeidler A. et al. (2014) High-pressure transformation of $\mathrm{SiO}_{2}$ glass from a tetrahedral to an octahedral network: A joint approach using neutron diffraction and molecular dynamics. Phys. Rev. Lett. 113, 135501-1-5.

\section{Appendix}

The covalent contribution to the cation-oxygen interaction energy was deduced from the theory of polar covalence proposed by Sanderson in the eighties (Sanderson, 1983, 1986, 1988). This theory divides the energy (E) of a polar covalent bond into two contributions, a nonpolar covalent energy $\left(E_{c}\right)$ and an ionic energy $\left(\mathrm{E}_{\mathrm{i}}\right)$,

$\mathrm{E}=\mathrm{t}_{\mathrm{c}} \mathrm{E}_{\mathrm{c}}+\mathrm{t}_{\mathrm{i}} \mathrm{E}_{\mathrm{i}}$

where $t_{i}$ and $t_{c}$ are blending coefficients $\left(t_{i}+t_{c}=1\right)$, and where $E_{i}$ is the Coulomb energy between unlike unit charges at the observed interatomic distance (bond length). The nonpolar covalent energy between atoms $\mathrm{A}$ and $\mathrm{B}, \mathrm{E}_{\mathrm{c}}$, is the geometric mean of the two homonuclear single covalent bond energies, $\mathrm{E}_{\mathrm{AA}}$ and $\mathrm{E}_{\mathrm{BB}}$, corrected for the difference between the actual bond length, $l$, and the sum of the nonpolar covalent radii, $\sigma$, by the simple factor $l / \sigma$,

$\mathrm{E}_{\mathrm{c}}=(l / \sigma)\left(\mathrm{E}_{\mathrm{AA}} \mathrm{E}_{\mathrm{BB}}\right)^{1 / 2}$

The ionic blending coefficient, $\mathrm{t}_{\mathrm{i}}$, is evaluated as half the difference between the partial charges of the two interacting atoms. These partial charges are based on the principle of electronegativity equalization and defined as the geometric mean of the individual atomic electronegativities. In using available data sources for a large variety of compounds, Sanderson $(1983,1986)$ has compiled the data needed for the evaluation of the nonpolar covalent energy, Ec, and the ionic blending coefficient, $\mathrm{t}_{\mathrm{i}}$. In practice, values of the ionic blending coefficient for cation-oxygen bonds in silicates are the following, 
$\mathrm{t}_{\mathrm{i}}=0.286(\mathrm{Si}-\mathrm{O}), 0.437(\mathrm{Ti}-\mathrm{O}), 0.383(\mathrm{Al}-\mathrm{O}), 0.273\left(\mathrm{Fe}^{3+}\right), 0.402\left(\mathrm{Fe}^{2+}\right), 0.486(\mathrm{Mg}-\mathrm{O}), 0.598(\mathrm{Ca}-\mathrm{O})$,

$0.741(\mathrm{Na}-\mathrm{O})$, and $0.793(\mathrm{~K}-\mathrm{O})$

One notices that, as expected, the $\mathrm{Si}-\mathrm{O}$ bond is highly covalent when the Na-O bond is mostly ionic. In the same way, it is easy to deduce from Sanderson's data the cation-oxygen covalent energies, $\mathrm{E}_{\mathrm{c}}$, and the covalent contribution, $\mathrm{t}_{\mathrm{c}} \mathrm{E}_{\mathrm{c}}$, to the bond energy $\mathrm{E}$ (see A1).

We have assumed that in our force field for silicates the covalent contribution to the cation-oxygen interaction energy can be modelled by a Gaussian function,

$$
v_{c}\left(r_{X O}\right)=-A_{X O} e^{-\left(\frac{r_{X O}-l_{X O}}{\lambda}\right)^{2}}
$$

where $r_{X O}$ is the cation-oxygen distance, $l_{X O}$ the bond length, and where $A_{X O}$ and $\lambda$ are parameters. Of course, one cannot expect that the value of $\mathrm{t}_{\mathrm{c}} \mathrm{E}_{\mathrm{c}}$ derived above (not shown) is sufficiently accurate to be assigned straightforwardly to the potential parameter, $A_{X O}$, describing the covalent energy in our force field. In fact, it is well known in quantum chemistry that the absolute magnitude of the interaction energy deduced from an approximate theory is rarely accurate but the trend for a series of compounds is generally correct. Then we have normalized the nonpolar covalent energy contribution for the different cation-oxygen bonds by the one of the Si-O bond. This rationale leads to the following hierarchy for the potential parameter $A_{i j}$,

$$
\begin{aligned}
A_{X O} / A_{\text {SiO }}= & 1(\mathrm{Si}-\mathrm{O}), 0.644(\mathrm{Ti}-\mathrm{O}), 0.786(\mathrm{Al}-\mathrm{O}), 0.813\left(\mathrm{Fe}^{3+}-\mathrm{O}\right), 0.604\left(\mathrm{Fe}^{2+}-\mathrm{O}\right), 0.568(\mathrm{Mg}-\mathrm{O}), \\
& 0.372(\mathrm{Ca}-\mathrm{O}), 0.156(\mathrm{Na}-\mathrm{O}), \text { and } 0.113(\mathrm{~K}-\mathrm{O})
\end{aligned}
$$

There are only two parameters to adjust $\left(A_{S i O}\right.$ and $\left.\lambda\right)$, the cation-oxygen bond lengths $\left(l_{X O}\right)$ in silicates being known (e.g. Brown et al., 1995). For $\lambda$ we have used the same value for all the cation-oxygen pairs $(\lambda=0.1414 \mathrm{~A})$, whereas $A_{S i O}$ was adjusted so as the self-diffusion coefficients of $\mathrm{O}$ and $\mathrm{Si}$ in various silicate melts show the correct order of magnitude. The final values of the parameters are given in Table 1.

The term proportional to $\sim 1 / \mathrm{r}^{6}$ in Eq.(1) corresponds to the atom-atom dispersion energy. The corresponding dipole-dipole London dispersion coefficient, $C_{i j}$, can be evaluated with the SlaterKirkwood formula (Koutselos and Mason, 1986),

$C_{i j}=\frac{3}{2} \frac{\alpha_{i} \alpha_{j}}{\left(\frac{\alpha_{i}}{N_{i}^{\text {eff }}}\right)^{1 / 2}+\left(\frac{\alpha_{j}}{N_{j}^{\text {eff }}}\right)^{1 / 2}} e^{2} a_{0}^{5}$

where $\alpha_{i}$ and $\alpha_{j}$ are dipole polarizabilities of the atoms $i$ and $j, N_{i}^{\text {eff }}$ and $N_{j}^{\text {eff }}$ are the effective numbers of electrons associated with atoms $i$ and $j$, and where $e$ and $a_{0}$ are the electron charge and the Bohr radius, respectively. For the ionic species in the silicate melt $\left(\mathrm{O}, \mathrm{Si}, \mathrm{Ti}, \mathrm{Al}, \mathrm{Fe}^{3+}, \mathrm{Fe}^{2+}, \mathrm{Mg}, \mathrm{Ca}\right.$, $\mathrm{Na}$ and K) we have used the dielectric polarizabilities by Shannon (1993). These polarizabilities were obtained by applying the Clausius-Mosotti relation (Lasaga and Cygan, 1982) to a large set of dieletric constant data for various oxides and silicate minerals with the assumption that the polarizability of a complex substance (e.g. a silicate) can be expressed as a sum of the constituent ion polarizabilities (for 
a review see Shannon and Fisher, 2006). It is only recently that it has become possible to evaluate ionic polarizabilities in condensed phase by ab initio calculation (Heaton et al., 2006; Salanne et al., 2008). For instance the distribution of the oxide anion polarizability in silicate melts of various composition (silica, rhyolite, basalt and enstatite) is rather broad with a most probable value about 1.5$2.0 \mathrm{~A}^{3}$ (Salanne et al., 2008), a value in accordance with the empirical determination of Shannon ( 2.0 $\mathrm{A}^{3}$ ). In absence of a full set of $a b$ initio calculated cationic polarizabilities in silicates we proceeded with (A3) by introducing the polarizability values determined by Shannon (1993). Moreover, for the effective numbers of electrons associated with ionic species we used the values of Grimes and Grimes (1998) which are deduced from a quantum mechanically-based equation relating ionic polarizability and effective number of electrons (see Table 1 in Grimes and Grimes, 1998). The final values of the $C_{i j}$ 's are given Table 1. 


\section{Table 1}

Potential parameters for silicate melts. Values of $A, l, B, \rho$, and $C$ given in column $3,4,5,6$, and 7 , respectively, correspond to oxygen-oxygen (raw 1) and cation-oxygen (raw 2 to 10) interactions, the cation-cation interactions being described only by repulsive Coulomb forces. Notice that there is no covalent interaction energy between oxygen atoms. The parameter $\lambda$ in the cation-oxygen covalent energy is equal to $0.1414 \mathrm{~A}$ (see Eq.(1) in the text).

\begin{tabular}{lcccccc}
\hline & $z(\mathrm{e})$ & $A(\mathrm{~kJ} / \mathrm{mol})$ & $l(\mathrm{~A})$ & $B(\mathrm{~kJ} / \mathrm{mol})$ & $\rho(\mathrm{A})$ & $C\left(\mathrm{~A}^{6} \mathrm{~kJ} / \mathrm{mol}\right)$ \\
\hline $\mathrm{O}$ & -0.945 & & & 153000.0 & 0.325 & 5259.83 \\
$\mathrm{Si}$ & 1.89 & 50.00 & 1.61 & 4869260.0 & 0.157 & 3036.49 \\
$\mathrm{Ti}$ & 1.89 & 32.20 & 1.90 & 5372350.0 & 0.182 & 9181.15 \\
$\mathrm{Al}$ & 1.4175 & 39.30 & 1.75 & 2681580.0 & 0.170 & 2564.84 \\
$\mathrm{Fe}$ & 1.4175 & 40.65 & 1.85 & 1761660.0 & 0.196 & 7034.76 \\
$\mathrm{Fe}$ & 0.945 & 30.20 & 2.05 & 2193830.0 & 0.194 & 6428.64 \\
$\mathrm{Mg}$ & 0.945 & 28.40 & 2.00 & 3275780.0 & 0.180 & 3912.70 \\
$\mathrm{Ca}$ & 0.945 & 18.60 & 2.40 & 15640400.0 & 0.179 & 8271.30 \\
$\mathrm{Na}$ & 0.4725 & 7.80 & 2.47 & 11937700.0 & 0.173 & 4673.81 \\
$\mathrm{~K}$ & 0.4725 & 5.65 & 2.90 & 941307.0 & 0.242 & 8653.71
\end{tabular}


Table 2

Chemical compositions of melt and coexisting solid phase (perovskite) in the simulated MORB at $3273 \mathrm{~K}$ and $60 \mathrm{GPa}$. The reported numbers express the ratio between the number of atoms of a given species in the investigated phase and the total number of atoms (including $\mathrm{O}$ ) in this phase. For instance, the solid phase is enriched in $\mathrm{Si}$ with respect to the MORB starting composition (indicated by Total).

\begin{tabular}{ccccccccccc}
\hline & $\mathrm{Si}$ & $\mathrm{Ti}$ & $\mathrm{Al}$ & $\mathrm{Fe}^{3+}$ & $\mathrm{Fe}^{2+}$ & $\mathrm{Mg}$ & $\mathrm{Ca}$ & $\mathrm{Na}$ & $\mathrm{K}$ \\
& & & & & & & & & \\
\hline Total & 0.1849 & 0.0043 & 0.0650 & 0.0030 & 0.0257 & 0.0423 & 0.0467 & 0.0213 & 0.0007 \\
Melt phase & 0.1307 & 0.0039 & 0.0856 & 0.0032 & 0.0142 & 0.0284 & 0.0081 & 0.0104 & 0.0004 \\
Solid phase & 0.2365 & 0.0048 & 0.0454 & 0.0028 & 0.0365 & 0.0555 & 0.0833 & 0.0317 & 0.0009
\end{tabular}




\section{Figures}

Fig. 1 Compressibility of the MORB melt between $1673 \mathrm{~K}$ and $3273 \mathrm{~K}$. The continuous curves are the simulation results fitted by a third-order BMEOS (with $T_{0}=1673 \mathrm{~K}, n_{\text {ref }}^{0}=2.65 \mathrm{~g} / \mathrm{cm}^{3}, \alpha_{0}=0.7010^{-}$ ${ }^{4} \mathrm{~K}^{-1}, \alpha_{1}=1.510^{-8} \mathrm{~K}^{-2}, K_{T_{0}}=20.5 \mathrm{GPa}, b_{1}=3.510^{-4} \mathrm{~K}^{-1}, b_{2}=-5.510^{-8} \mathrm{~K}^{-2}$, and $\left.K^{\prime}=5.2\right)$. In the main panel the calculated isotherms $(1673-2673 \mathrm{~K})$ are separated by $200 \mathrm{~K}$ and the symbols represent some experimental data. The full dot is the density value at $1673 \mathrm{~K}$ given by Lange and Carmichael (1987), the square is the measurement of Agee (1998) at $1950 \mathrm{~K}$, the empty triangles are the density data of Sakamaki et al. (2013) between $1673 \mathrm{~K}$ and $2000 \mathrm{~K}$, the full triangles are those of Ohtani and Maeda (2001) at $2473 \mathrm{~K}$ and $2773 \mathrm{~K}$, and the circles are the high-temperature high-pressure data (2200-3273 K, 10.5-60 GPa) of Sanloup et al. (2013). One notices that the latter density data deviate significantly from all the other ones (these densities are much higher and especially above $2600 \mathrm{~K}$ where they match density values observed with MORB solid phases, see Fig.2 for a comparison). In the inset the crystallization of the simulated MORB melt along the isotherm $3273 \mathrm{~K}$ is shown (see the red curve, color online, and how the density is changing abruptly at about $50 \mathrm{GPa}$ ). Notice that along the liquid branch of the isotherm $3273 \mathrm{~K}$, the third-order BMEOS (the black curve) deviates slightly from the MD raw data (the red wiggling curve, color online) above $\sim 35 \mathrm{GPa}$, a deviation which can be mitigated by the use of a fourth-order BMEOS (not shown). The crosses correspond to the firstprinciples simulation data of Bajgain et al. (2015) along the isotherm $3000 \mathrm{~K}$ in using the LDA approximation, and the crossed circles are those using the more accurate GGA approximation.

Fig.2 Density of the simulated MORB at high-pressure-high temperature (perovskite phase) compared to experimental data and PREM. The full curves are MD-generated isotherms at 1750, 2400 and 2600 $\mathrm{K}$ and are fitted by a third-order BMEOS (with $T_{0}=300 \mathrm{~K}, n_{r e f}=4.25 \mathrm{~g} / \mathrm{cm} 3, \alpha_{0}=2.5910^{-5} \mathrm{~K}^{-1}, K_{T_{0}}=$ $223 \mathrm{GPa}, b_{l}=8.9410^{-6} \mathrm{~K}^{-1}$, and $\left.K^{\prime}=4\right)$. Circles are density data of Ono et al. (2005) between $2070 \mathrm{~K}$ and $2410 \mathrm{~K}$, crosses are those of Hirose et al. (2005) between $1750 \mathrm{~K}$ and $2290 \mathrm{~K}$, and triangles are those of Ricolleau et al. (2010) in the T range $2200-2300 \mathrm{~K}$ (empty triangles) and $2400-2700 \mathrm{~K}$ (full triangles), respectively. The dotted line is the PREM density profile (Dziewonski and Anderson, 1981) which intersects the $2600 \mathrm{~K}$ isotherm of the simulated MORB at about $50 \mathrm{GPa}$. The inset shows a MORB melting line obtained by MD simulation (the curve labelled L-S) and located somewhere in between the liquidus and the solidus (see text). The full and empty circles represent respectively the solidus and the liquidus determined by Andrault et al. (2014) and the red triangles (color online) correspond to the solidus obtained by Pradhan et al. (2015). The star at $3273 \mathrm{~K}$ and $60 \mathrm{GPa}$ (indicated by $\mathrm{S}$ in the figure) is our estimation of the MORB solidus at this pressure: it is very close to the evaluation of Pradhan et al. (2015). 
Fig.3 X-ray pair distribution function for the simulated MORB melt at $1673 \mathrm{~K}$ and $0 \mathrm{GPa}$. The ten most contributing pair distribution functions are shown (color online) and are shifted vertically for clarity. The assignments of pics and shoulder indexed by letters are the following: $\mathbf{a}(\mathrm{Si}-\mathrm{O}), \mathbf{b}\left(\mathrm{Fe}^{2+}-\mathrm{O}\right.$ $+\mathrm{Mg}-\mathrm{O}), \mathbf{c}(\mathrm{Ca}-\mathrm{O}+\mathrm{Na}-\mathrm{O}), \mathbf{d}(\mathrm{OO}), \mathbf{e}(\mathrm{SiSi}), \mathbf{f}\left((\mathrm{SiO})_{2}\right), \mathbf{g}\left((\mathrm{OO})_{2}+\left(\mathrm{SiSi}_{2}\right), \mathbf{h}\left((\mathrm{SiO})_{3}\right)\right.$, and $\mathbf{i}\left((\mathrm{SiSi})_{3}\right.$ $\left.+(\mathrm{OO})_{3}\right)$. Notice that the Al-O bond located around $1.75 \mathrm{~A}$ is buried into the $\mathrm{Si}-\mathrm{O}$ pic (a) and that the contributions of Ti-O and $\mathrm{Fe}^{3+}-\mathrm{O}$ bonds fill in part the first minimum of $\mathrm{G}_{\mathrm{X}}(\mathrm{R})$ located at about 1.90 A.

Fig.4 Evolution with pressure of the X-ray pair distribution function. The assignments of peaks $\mathbf{a}, \mathbf{b}, \mathbf{c}$, $\mathbf{d}, \mathbf{e}, \mathbf{f}, \mathbf{g}, \mathbf{h}$, and $\mathbf{i}$ are the same as those given in Fig.3. In the perovskite phase (Pv) the peaks $\mathbf{b}, \mathbf{h}$, and $\mathbf{i}$ are barely visible whereas three new peaks are appearing (d', $\mathbf{g}^{\prime}$, and $\mathbf{j}$ ) with the following assignment: d' $\left(\mathrm{Si}: \mathrm{Ca}, \mathrm{Fe}^{2+}, \mathrm{Mg}, \mathrm{Na}\right), \mathbf{g}$ ' $\left(\left(\mathrm{Si}: \mathrm{Ca}, \mathrm{Fe}^{2+}, \mathrm{Mg}, \mathrm{Na}\right)_{2}\right)$, and $\mathbf{j}\left((\mathrm{SiSi})_{5}+(\mathrm{SiO})_{5}+(\mathrm{Si}: \mathrm{Ca}\right.$ $\left.\left., \mathrm{Fe}^{2+}, \mathrm{Mg}, \mathrm{Na}\right)_{3}\right)$.

Fig.5 Evolution of the cation coordination number with the pressure (color online). Notice that the temperature evolves with the pressure in the following way: $0 \mathrm{GPa}(1673 \mathrm{~K}), 3 \mathrm{GPa}(1873 \mathrm{~K}), 5 \mathrm{GPa}$ $(1873 \mathrm{~K}), 8 \mathrm{GPa}(2073 \mathrm{~K}), 10 \mathrm{GPa}(2273 \mathrm{~K}), 15 \mathrm{GPa}(2273 \mathrm{~K}), 20 \mathrm{GPa}(2673 \mathrm{~K}), 25 \mathrm{GPa}(2673 \mathrm{~K})$, $30 \mathrm{GPa}(3273 \mathrm{~K}), 35 \mathrm{GPa}(3273 \mathrm{~K}), 40 \mathrm{GPa}(3273 \mathrm{~K})$, and $45 \mathrm{GPa}(3273 \mathrm{~K})$. With the latter conditions the simulated system exhibits a perovskite-like structure (see text).

Fig.6 Viscosity of the simulated MORB melt as function of the temperature at atmospheric pressure. Experimental data of the literature are also shown (color online). The dotted curve represents a hightemperature extrapolation of the Villeneuve et al. (2008) data.

Fig.7 Viscosity of the simulated MORB melt as function of pressure and temperature. The data of Sakamaki et al. (2013) are shown for comparison.

Fig.8 Electrical conductivity of the simulated MORB melt as function of the temperature. Experimental data of the literature are also shown (color online). The numbers indicate the pressure (in $\mathrm{GPa}$ ) at which the conductivity was evaluated (or measured).

Fig.9 Electrical conductivity of the simulated MORB melt as function of the pressure. Notice that the data of Tyburczy and Waff (1983) are at $1673 \mathrm{~K}$.

Fig.10 Self-diffusion coefficients of elements in the simulated MORB melt at atmospheric pressure (color online). Symbols and dotted curves are simulation data and lines $(\mathbf{a}, \mathbf{b}, \mathbf{c}, \mathbf{d}, \mathbf{e}$, and f) are experimental data. Reference key: a - Na - Lowry et al. (1982); b - Mg - LaTourrette et al. (1996); c 
- Ca - LaTourrette et al. (1996); d - $\mathrm{Fe}^{3+}$ - Lowry et al. (1982); e-Ti-LaTourrette et al. (1996); $\mathbf{f}$ - O, Si - Lesher et al. (1996), note that the distinction between $\mathrm{O}$ and $\mathrm{Si}$ is barely visible.

Fig.11 Self-diffusion coefficients of elements in the simulated MORB melt as function of the pressure (color online). Symbols and dotted curves are simulation data and curves $(\mathbf{a}, \mathbf{b})$ are experimental data. Reference key: a - O in $\mathrm{Di}_{58} \mathrm{An}_{42}$ at $1986 \mathrm{~K}$ - Tinker et al. (2003); b- Si in $\mathrm{Di}_{58} \mathrm{An}_{42}$ at $1986 \mathrm{~K}-$ Tinker et al. (2003).

Fig.12 Electrical conductivity $(\sigma)$ as function of the Nernst-Einstein conductivity $\left(\sigma_{\mathrm{NE}}\right)$. Filled circles represent the raw data and the empty circles are the data corrected by applying a constant Haven ratio $\left(H_{R}\right)$ equal to 3.7 (see Eq.(12) in the text).

Fig.13 Evolution of the product of the viscosity by the electrical conductivity as function of temperature and pressure. The lines represent isobars. 


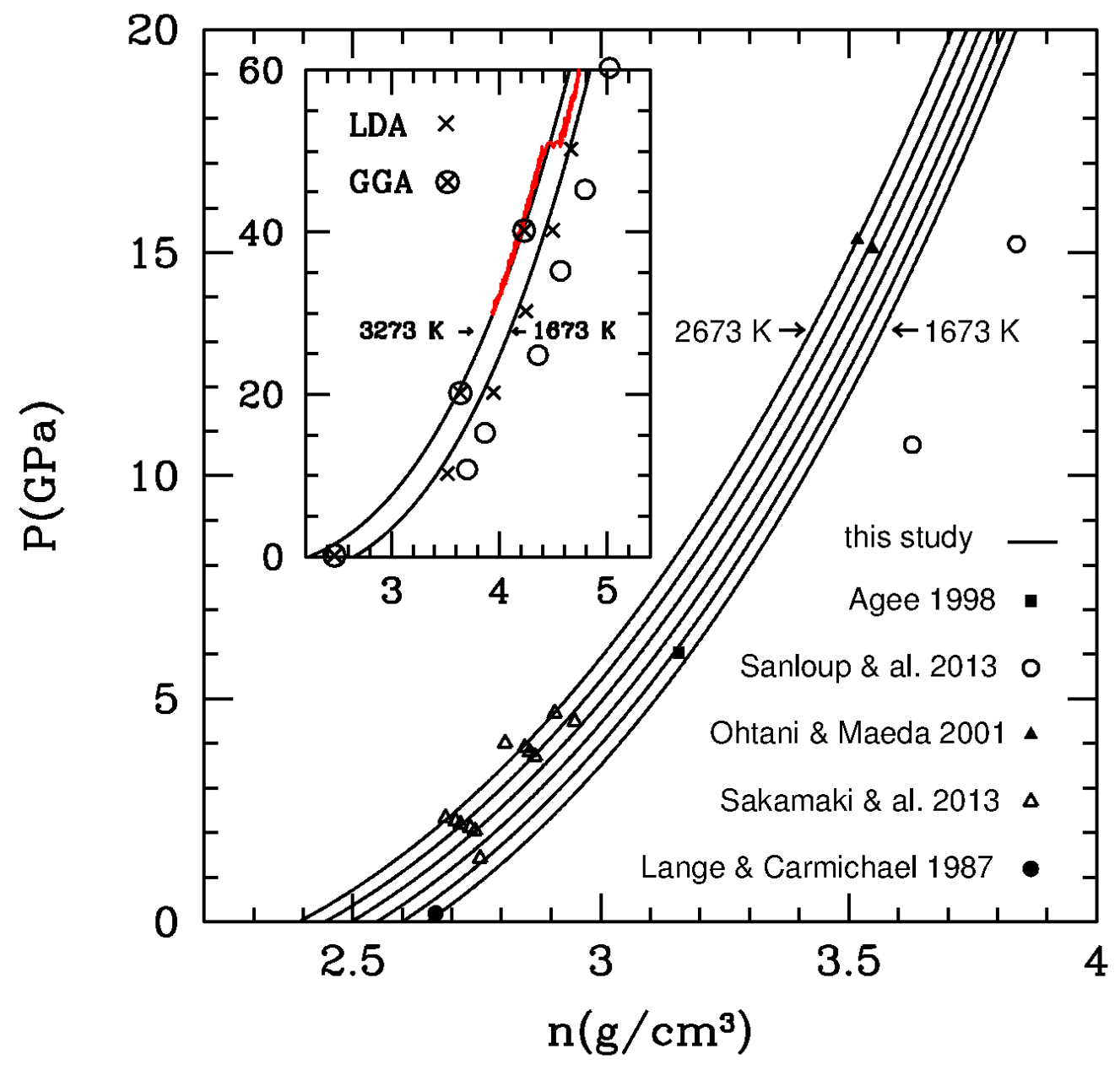

Fig.1 


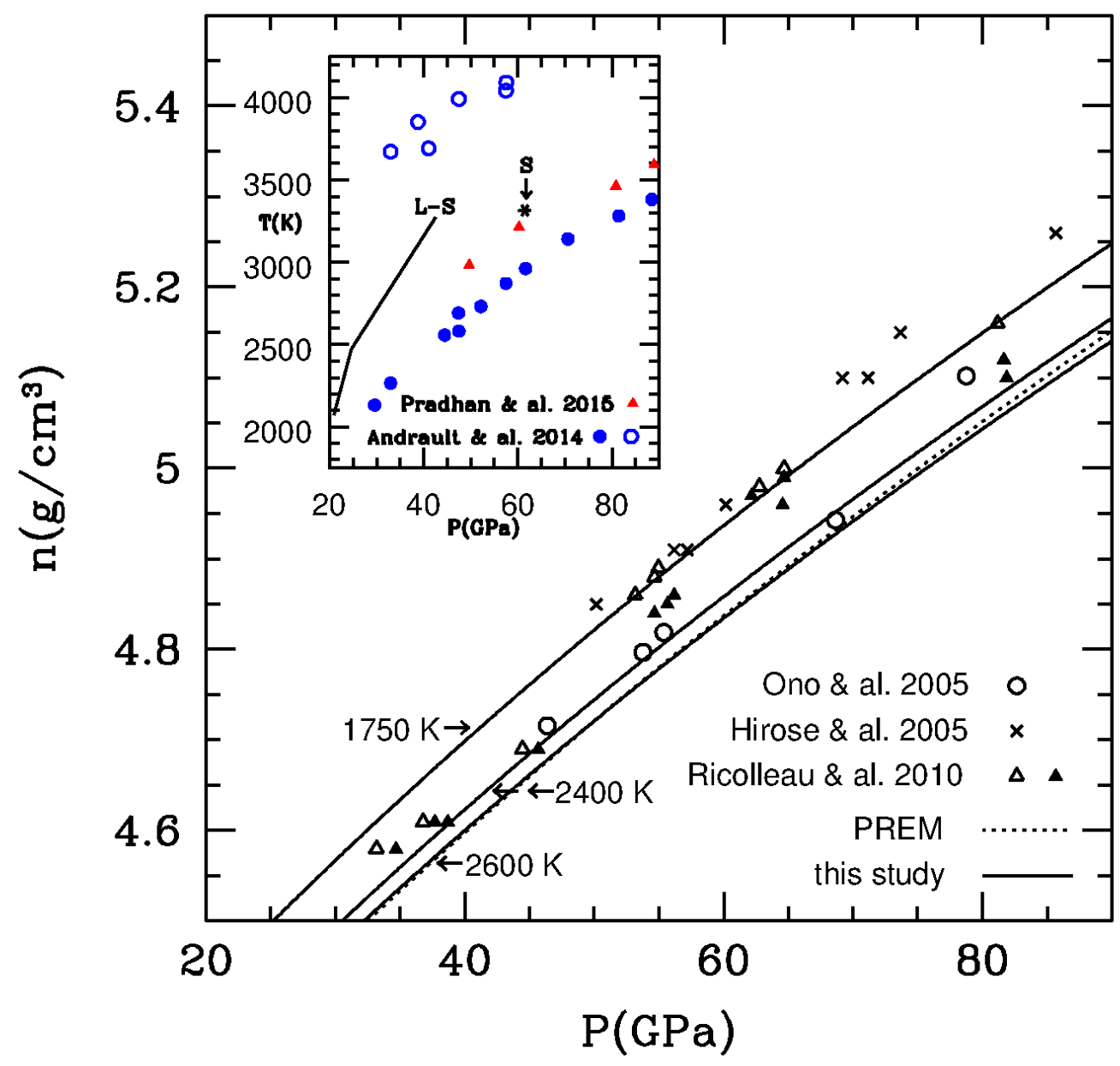

Fig.2 


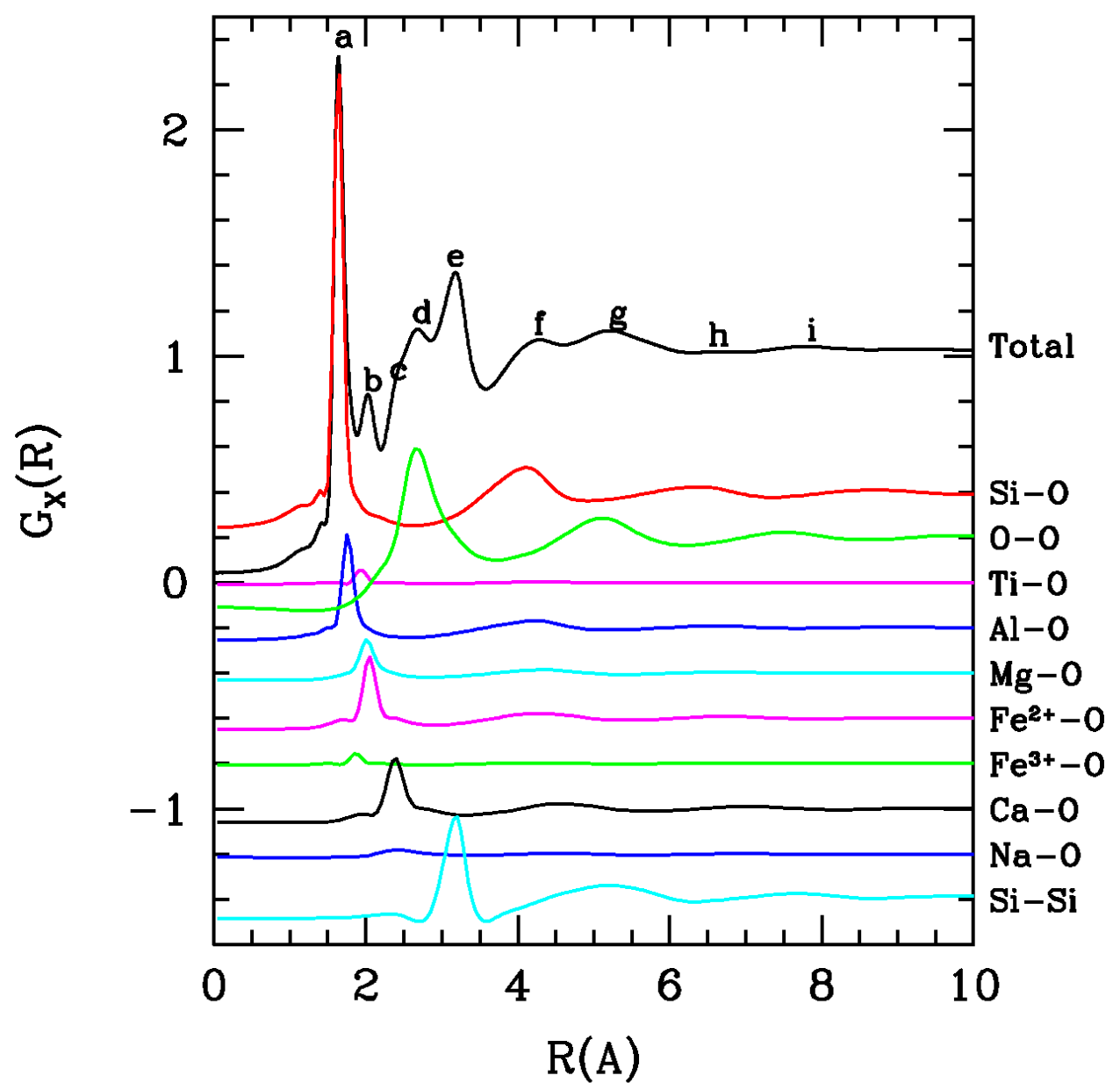

Fig.3 


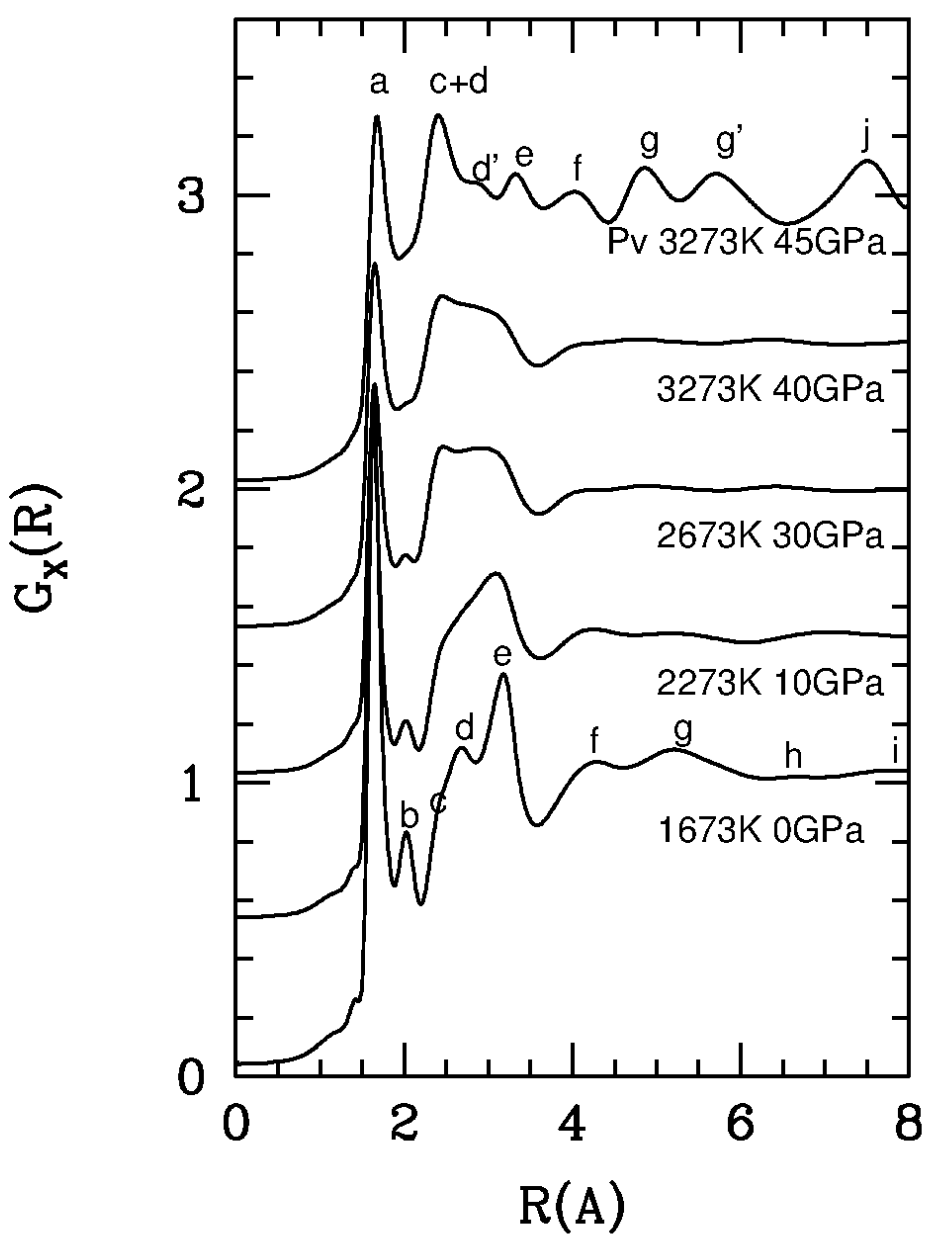

Fig.4 


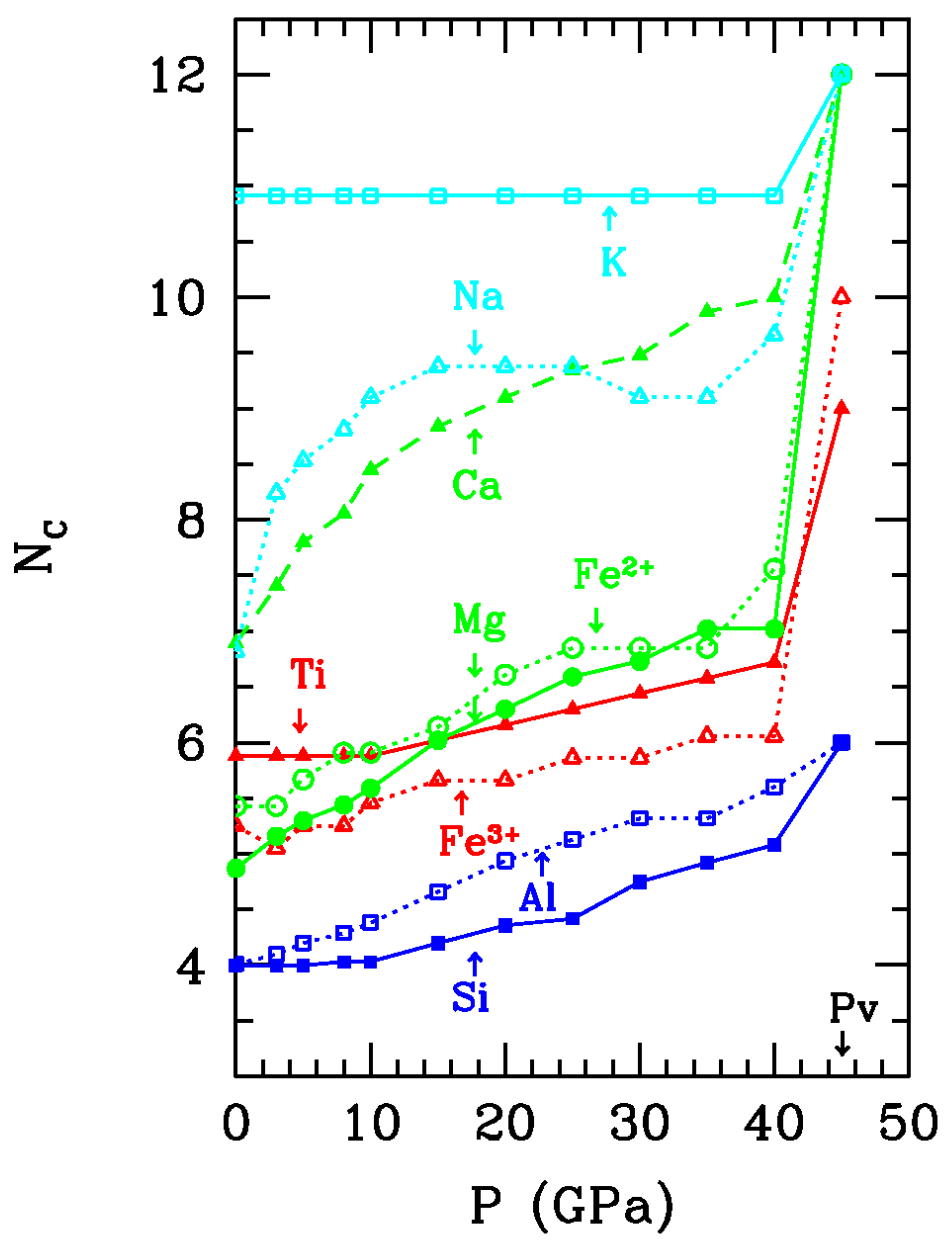

Fig.5 


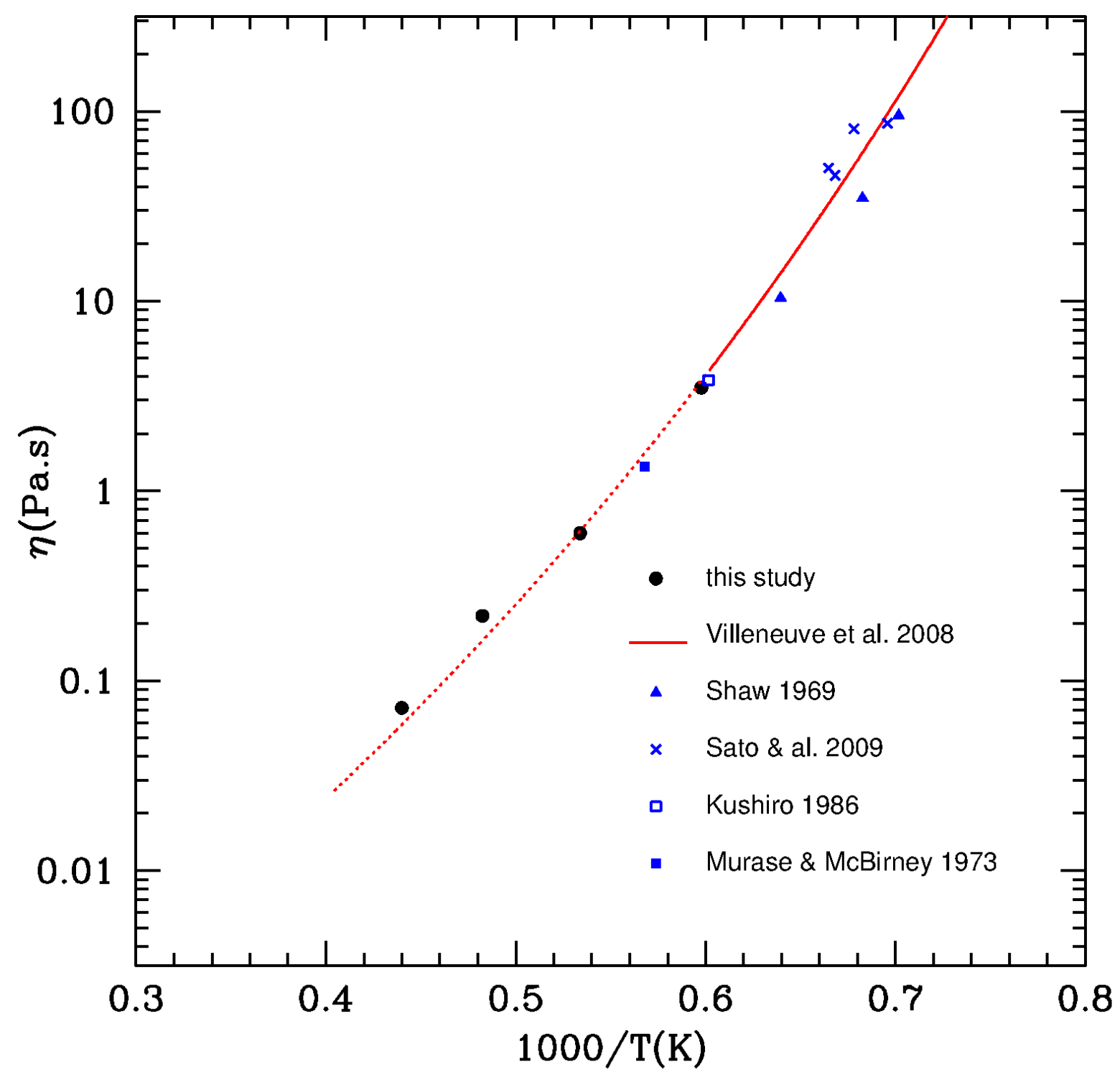

Fig.6 


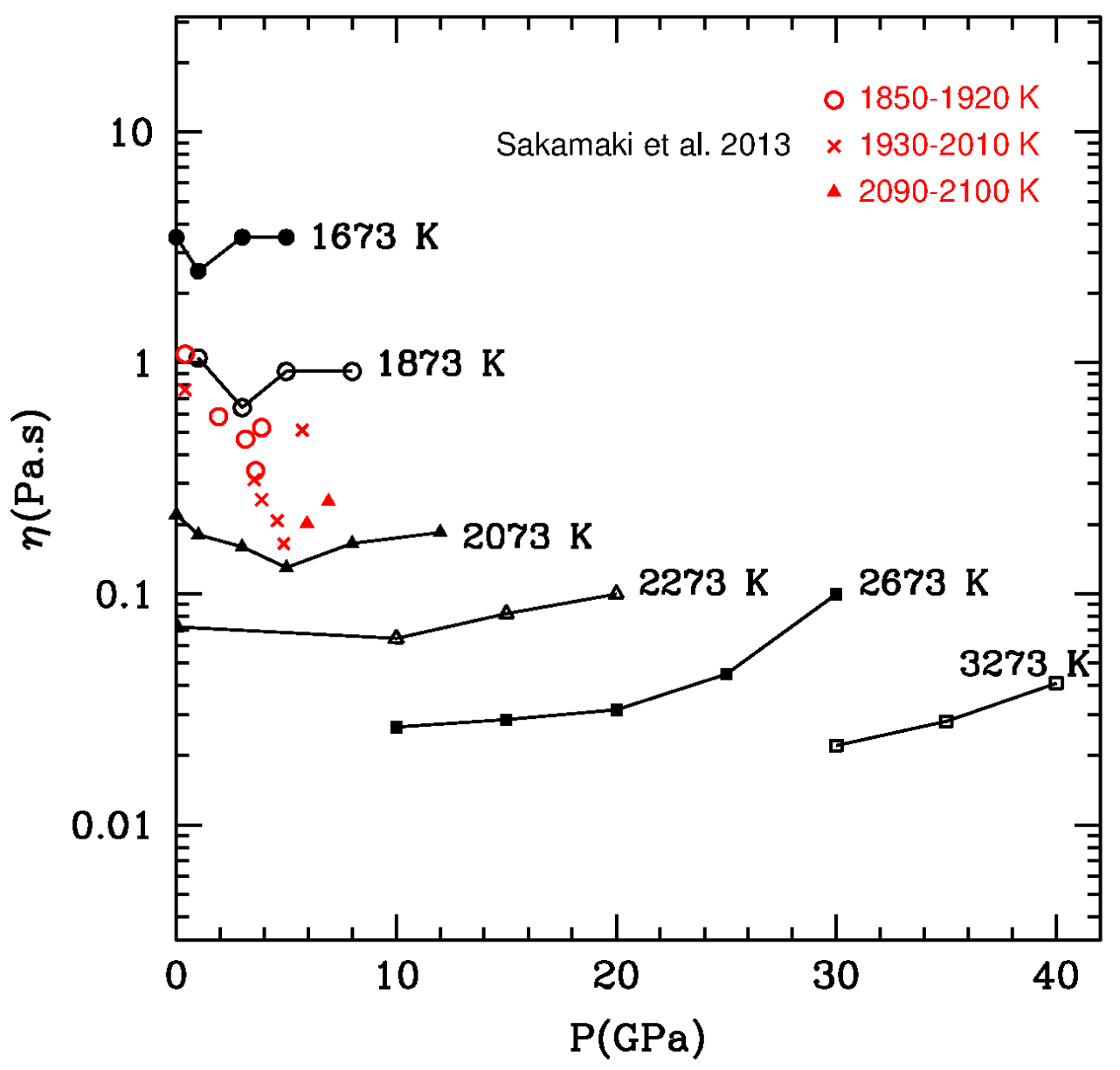

Fig.7 


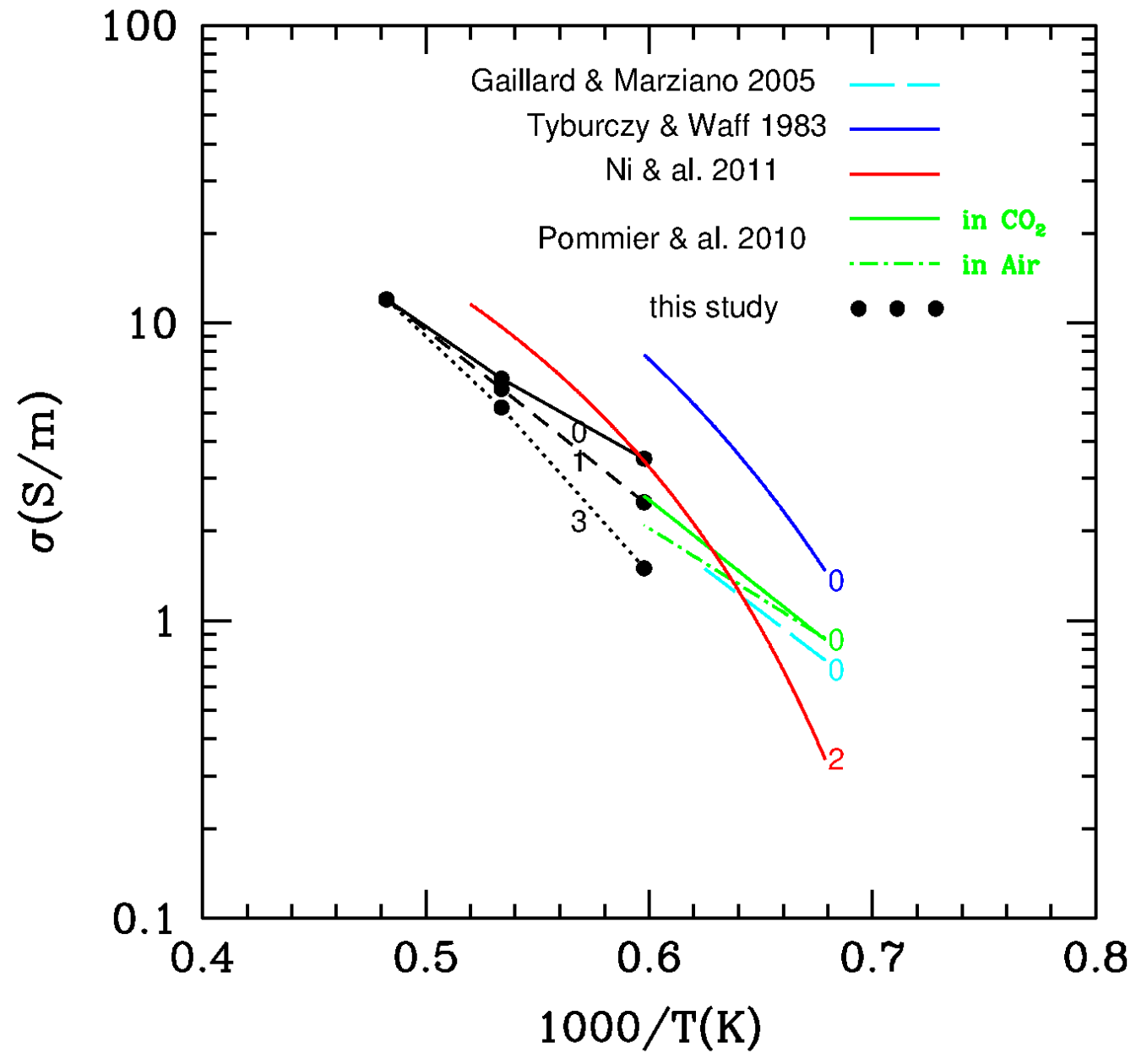

Fig.8 


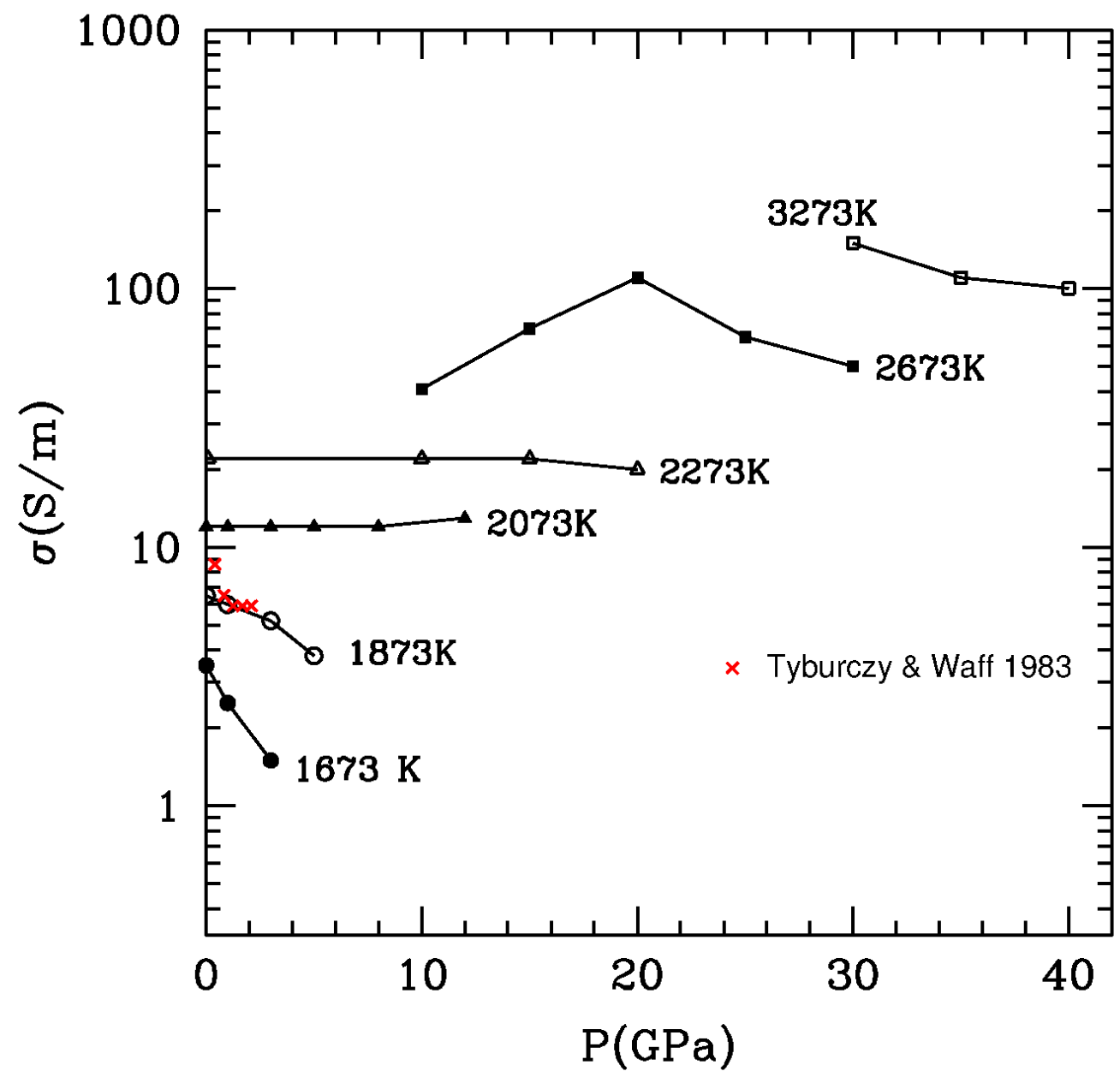

Fig.9 


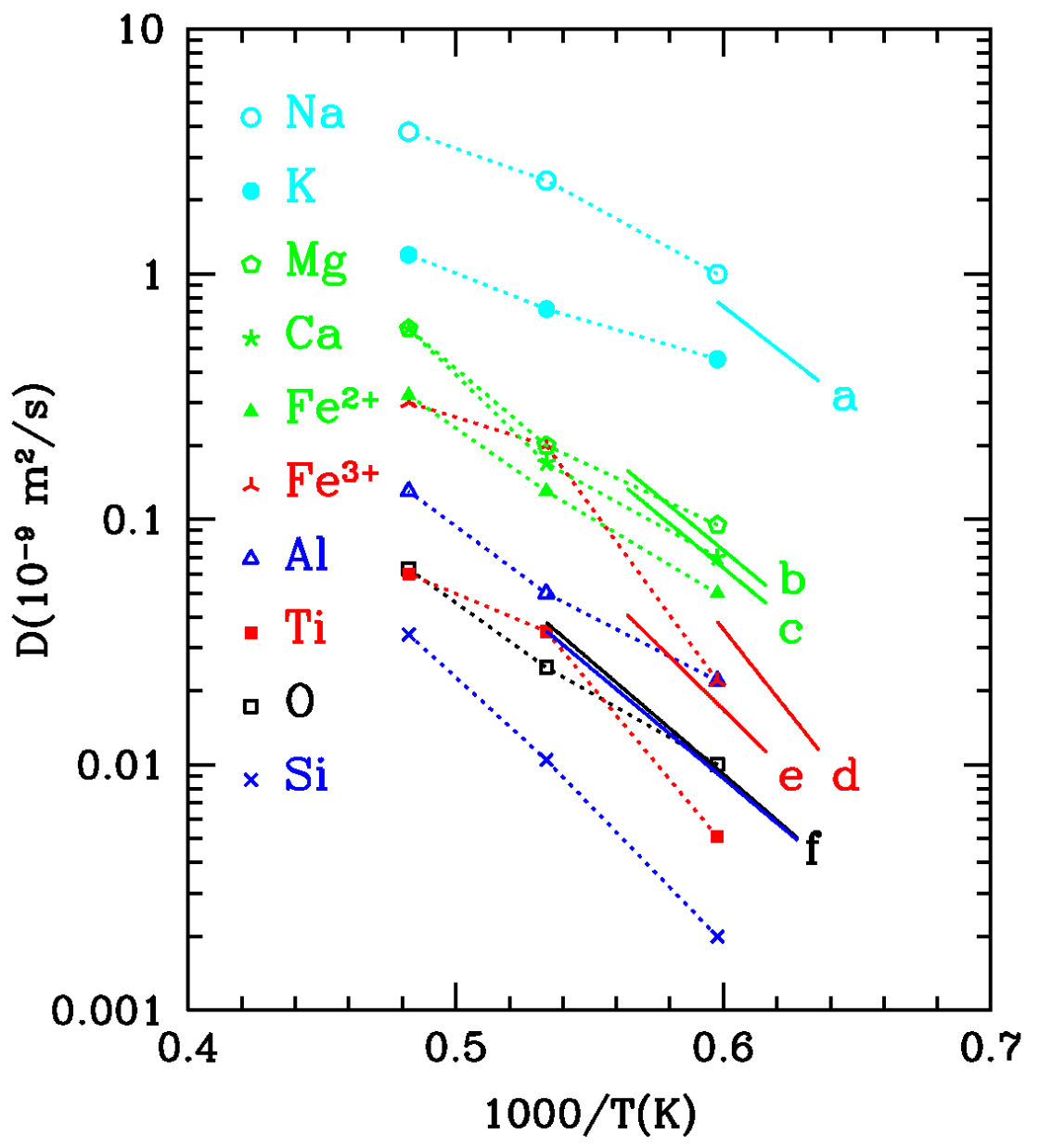

Fig.10 

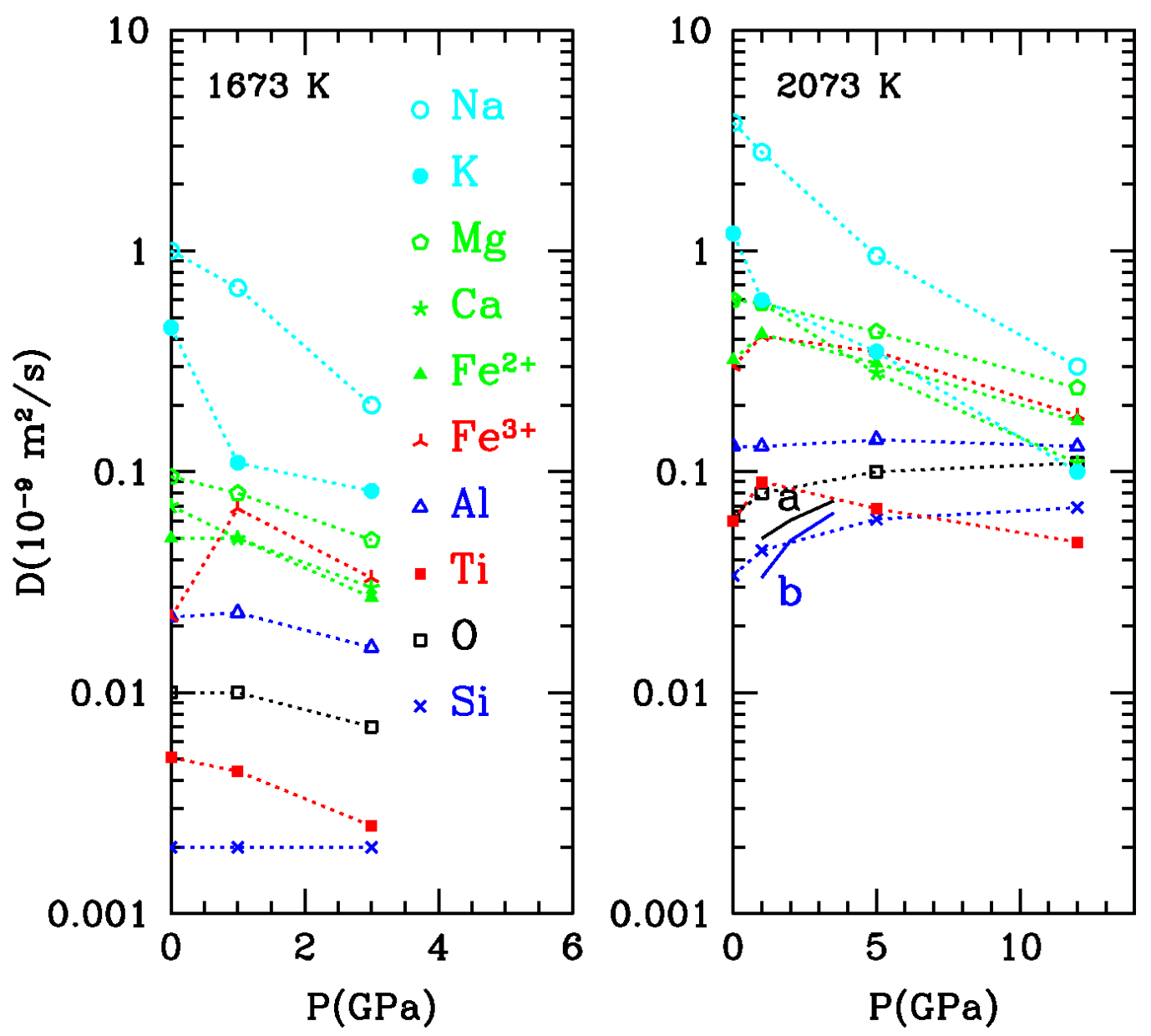

Fig.11 


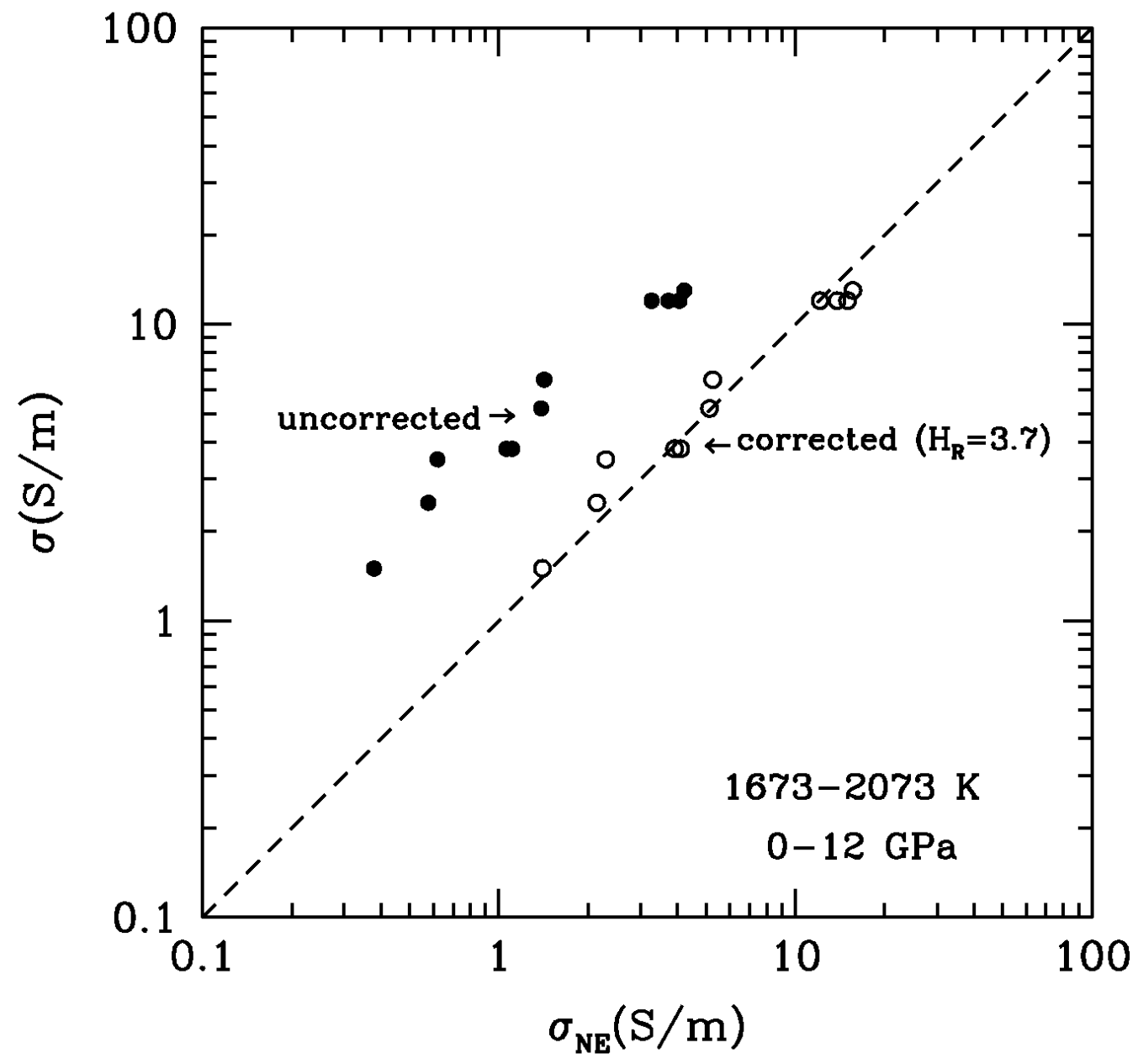

Fig.12 


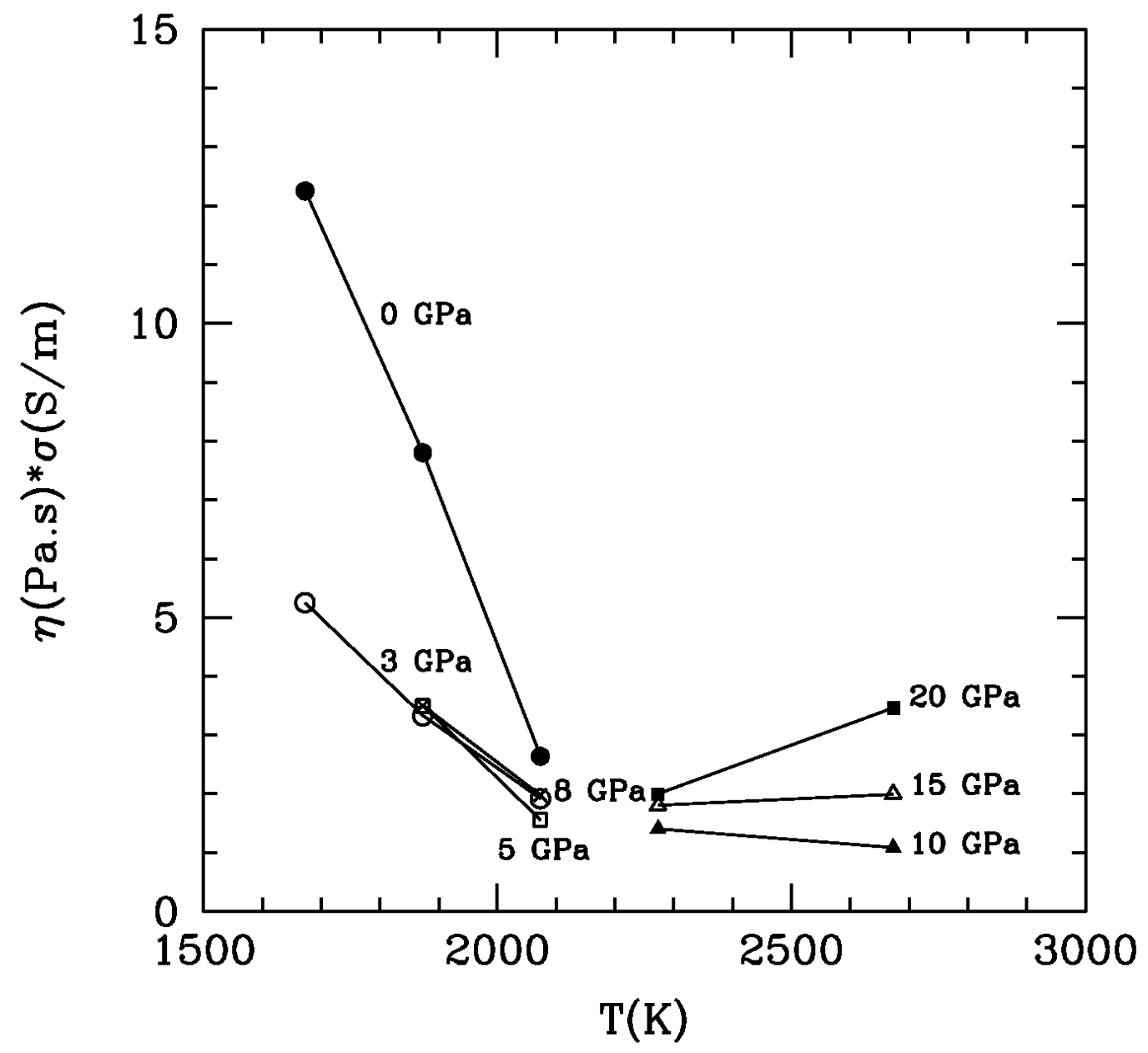

Fig.13 